
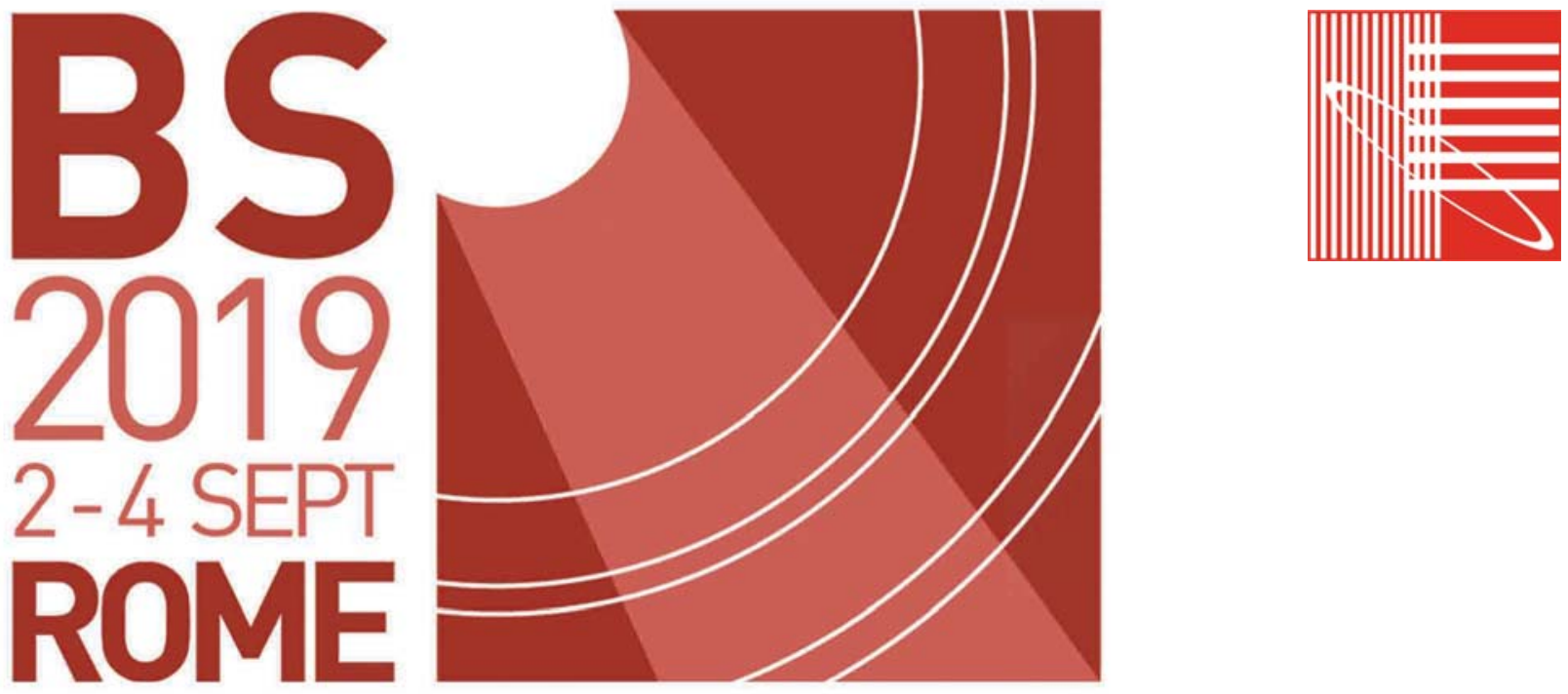

INTERNATIONAL BUILDING PERFORMANCE SIMULATION ASSOCIATION

\title{
Proceedings of Building Simulation 2019: 16th Conference of IBPSA
} edited by

V. Corrado, E. Fabrizio, A. Gasparella, and F. Patuzzi

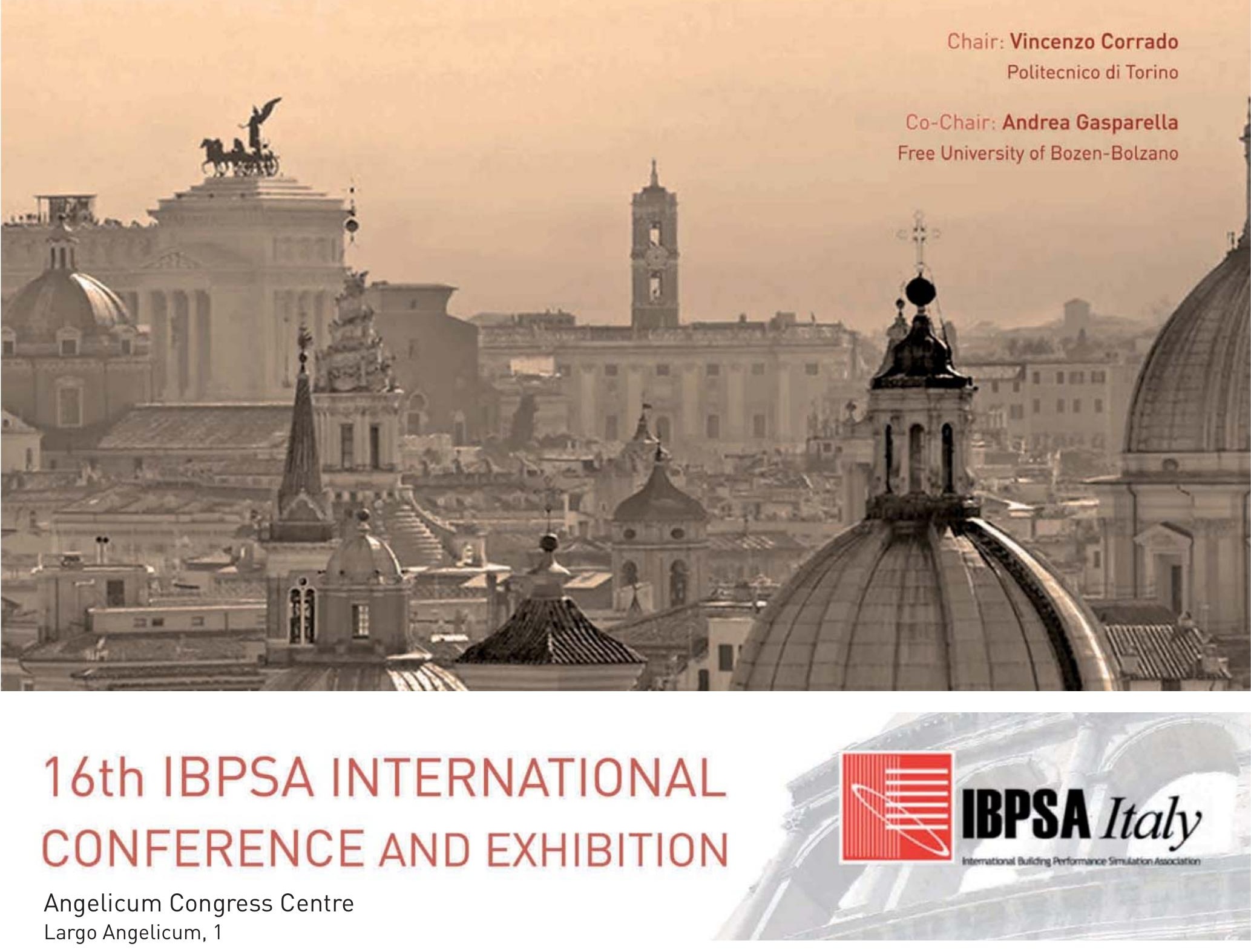




\title{
Conference Chairs
}

Vincenzo Corrado (Chair)

Andrea Gasparella (Co-Chair)

\section{Executive Scientific Committee}

Livio Mazzarella, Italy (President)

Luigi Marletta, Italy

Godfried Augenbroe, USA

Paolo Baggio, Italy

Ian Beausoleil-Morrison, Canada

Joe Clarke, UK

Vincenzo Corrado, Italy

Andrea Gasparella, Italy

Lieve Helsen, Belgium

Jan Hensen, Netherlands

Roberto Lamberts, Brazil

Ardeshir Mahdavi, Austria

Jyotirmay Mathur, India

Cheol-Soo Park, South Korea

Yoshiyuki Shimoda, Japan

Veronica Soebarto, Australia

Paul Strachan, UK

Athanasios Tzempelikos, USA

Christoph van Treeck, Germany

Michael Wetter, USA

Monika Woloszyn, France

Yingxin Zhu, China

\section{Local Organizing Committee}

Francesco Asdrubali (Secretary)

Ilaria Ballarini

Fabio Bisegna

Annamaria Buonomano

Filippo Calcerano

Alfonso Capozzoli

Francesca Cappelletti

Maurizio Cellura

Cristina Cornaro

Luca Evangelisti

\author{
Enrico Fabrizio \\ Claudia Guattari \\ Adolfo Palombo \\ Patrizia Pasolini \\ Francesco Patuzzi \\ Anna Laura Pisello \\ Elisa Polini \\ Alessandro Prada \\ Michele Zinzi
}

\section{Organized by}

Symposia srl

Venue: Angelicum Congress Centre, Rome, Italy

ISBN: 978-1-7750520-1-2

ISSN: 2522-2708

Proceedings of BS2019: 16th Conference of IBPSA

(C) International Building Performance Simulation Association, 2020

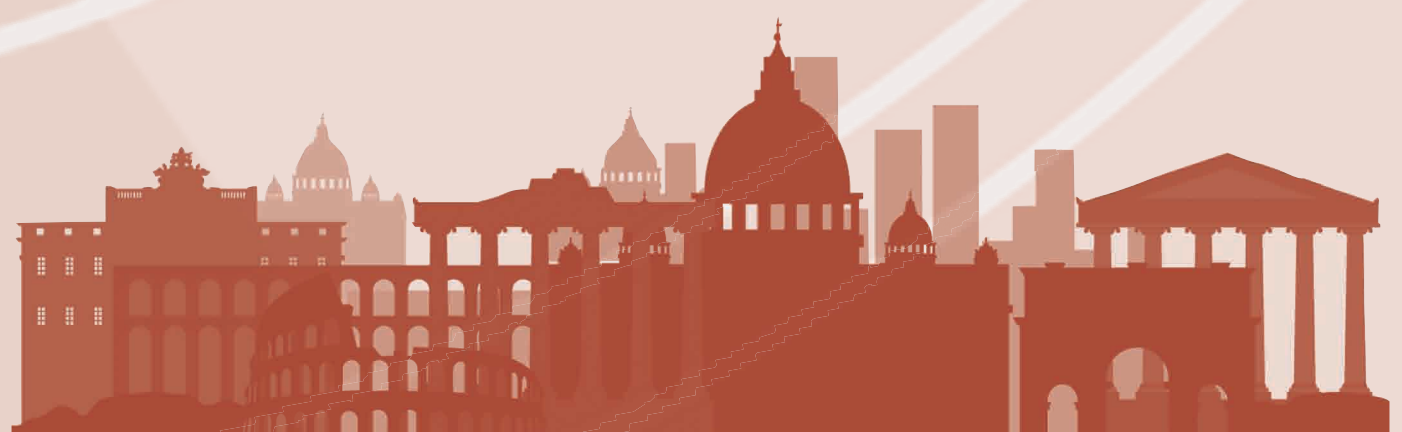




\section{List of topics}

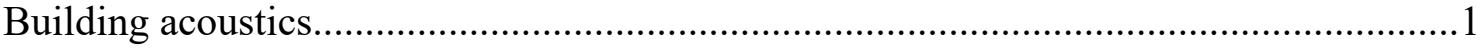

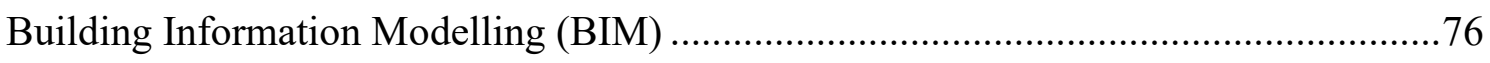

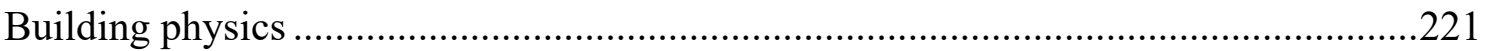

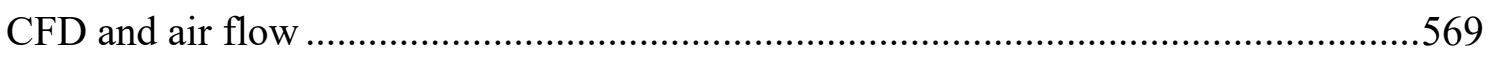

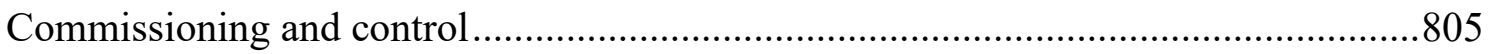

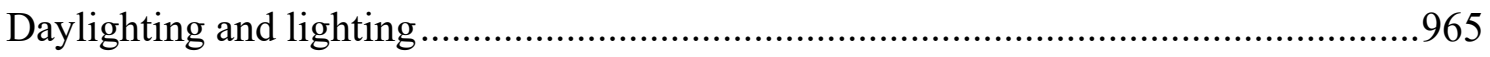

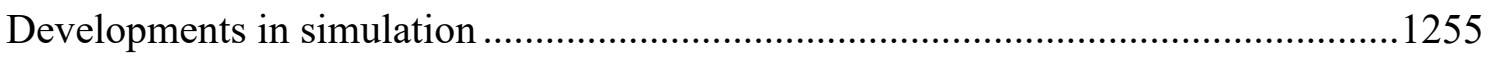

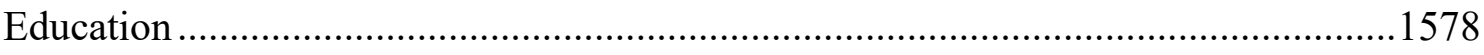

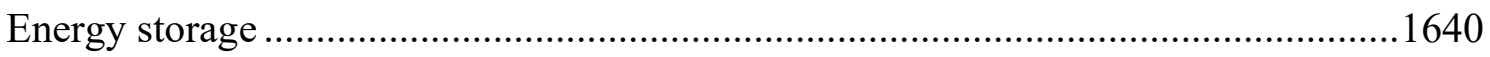

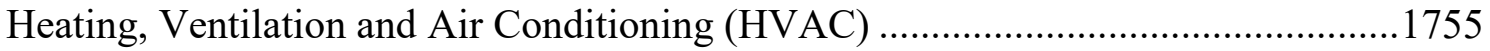

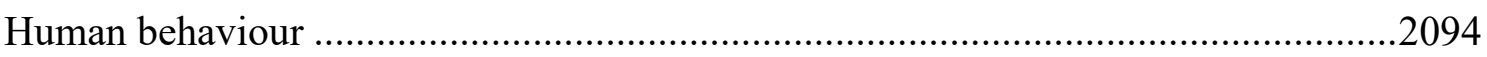

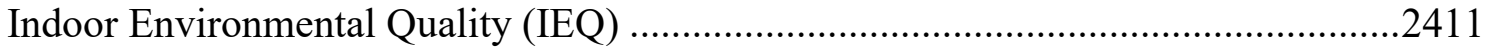

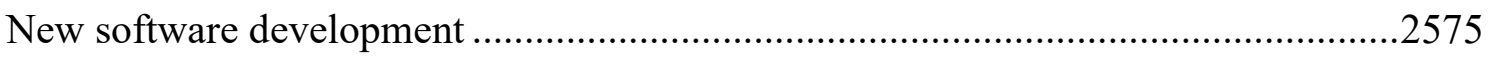

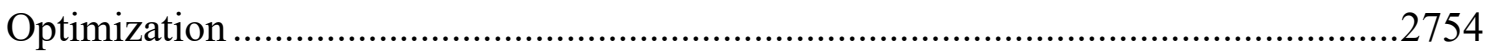

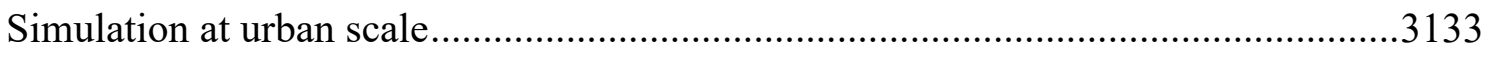

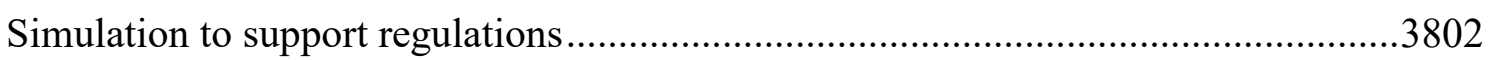

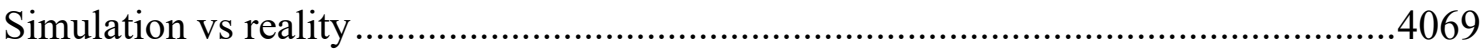

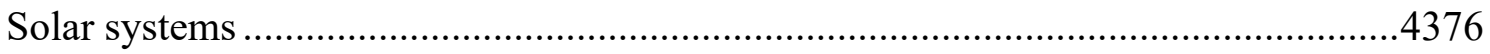

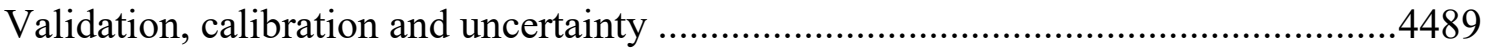

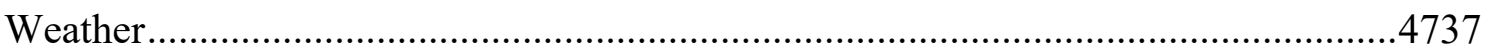

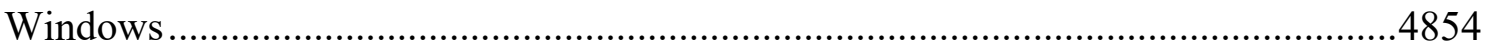

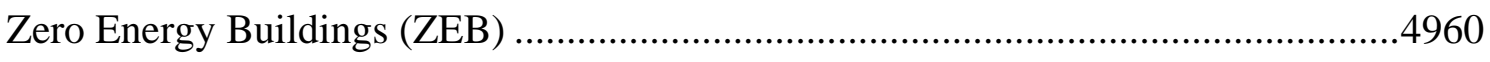

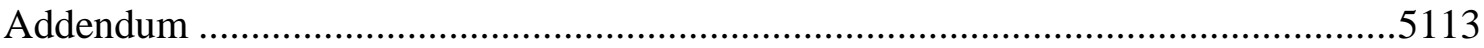




\section{List of papers}

Building acoustics.

Paper ID 210178

Integrated Acoustic and Thermo-Fluid Insulation Modeling of an Airflow Window with a

Photovoltaic Solar Wall

Himanshu Dehra

Paper ID 210391

Assessment of Reverberation Times in University Classroom: Comparison between Analytic

Formulae, Software Simulations and Measurements

Fabio Fantozzi, Michele Rocca, Nicola Spinelli

Paper ID 210605

Geometrical Acoustic Simulation of Open-air Ancient Theatres: Investigation on the Appropriate

Objective Parameters for Improved Accuracy

Elena Bo, Louena Shtrepi, Francesco Aletta, Giuseppina Emma Puglisi, Arianna Astolfi

Paper ID 210700

FEM Numerical Simulations To Predict The Vibration Reduction Index of Traditional And

Lightweight Building Junctions

Arianna Astolfi, Elena Caccherano, Alessio Carullo, Antonella Castellana, Alessia Griginis, Marco

Masoero, Giuseppina Emma Puglisi, Louena Shtrepi

Paper ID 210880

Aeroacoustic Facade Noise Validation: A Comparison of CFD and Wind Tunnel Tests

Nathaniel L Jones, Alexej Goehring

Paper ID 211044

Acoustical Analysis of Auditorium with Computer Aided Acoustic Simulation

Sumit Sanjay Gaikwad, S. Rajkumar.

Paper ID 211114

Innovative Approach in Acoustic Simulation of Timber Walls

Marco Caniato, Paolo Bonfiglio, Federica Bettarello, Andrea Gasparella

Paper ID 211184

On The Use Of The Transfer Matrix Method To Evaluate Sound Insulation In Complex Building

Partitions

Andrea Santoni, Patrizio Fausti, Paolo Bonfiglio, Marco Caniato

Paper ID 211379

BIM-based Simulation for Analysis of Reverberation Time

Joonhee Lee, Mazdak Nik-Bakht

Paper ID 211394

Simulation of the Transmission Loss of Curtain Wall with Mullions

Marco Caniato, Federica Bettarello, Andrea Gasparella 
Paper ID 210112

A Building Performance Indicator Ontology: Structure and Applications

Ardeshir Mahdavi, Mahnameh Taheri, Dawid Wolosiuk

Paper ID 210191

Rule-Based Views and Linked Building Data for Efficient Planning Processes

Christoph Maurer, Anna Wagner, Julian Wengzinek, Uwe Rüppel, Wendelin Sprenger, Tilmann E.

Kuhn .....

Paper ID 210241

BIM to Building Energy Performance Simulation: An Evaluation of Current Industry Transfer Processes

James Thomas O'Donnell, Megan van Dessel, Tobias Maile

Paper ID 210330

BIM2PHPP: A New BIM-Based Tool for Passivhaus Design With PHPP

Omar Sadeq Hamed, Tsung-Hsien Wang

Paper ID 210333

Optimized Renovation Strategies of Education Building - a novel BIM/BPM/BEM framework Ming $\mathrm{Hu}$

Paper ID 210374

Derive Urban Scale Occupant Behavior Profiles From Mobile Position Data: A Pilot Study

Bing Dong, Wenbo Wu, Qi Wang, Sadam Abdelmutaal, Vishnu Prakash.

Paper ID 210414

Reliability Of Daylight And Energy Demand Evaluations For Decision Making At The Conceptual Design Stage

Minu Agarwal, Gerald Danseux, Luisa Pastore, Marilyne Andersen

Paper ID 210442

From Heritage BIM to BPS, A Computational Design-Based Interoperability Approach

Elena Gigliarelli, Filippo Calcerano, Francesca D’Uffizi, Carla Di Biccari, Giovanna Mangialardi,

Massimo Campari.

Paper ID 210481

BIM-based Business Process Model To Support Systematic Deep Renovation Of Buildings

Letizia D'Angelo, Alessandro Piccinini, Federico Seri, Raymond Sterling, Andrea Costa, Marcus M.

Keane

Paper ID 210569

A Framework to Integrate Databases with Building Information Modelling for Building Energy

Assessment

Danny Lobos, Eric Henríquez Jara, David Blanco, Pablo Pulgar

Paper ID 210616

A BIM-based Life Cycle Cost (LCC) Method to Reduce the Operation Energy Costs in Buildings Yussra Mohamed Rashed, Ibrahim Abdul-Rashid Nosair, Khaled Nassar, Islam Ayman Mashaly, Meshary Ghanem

Paper ID 210634

Towards An Accessible Life Cycle Assessment: A Literature Based Review Of Current BIM And

Parametric Based Tools Capabilities

Carmine Cavalliere, Leonardo Brescia, Gaetano Maiorano, Tiziano Dalla Mora, Guido Raffaele

Dell'Osso, Emanuele Naboni

Paper ID 210689

A Workflow for Automated Building Energy Performance Model Generation Using BIM Data Georgios I Giannakis, Kyriakos I Katsigarakis, Georgios Nektarios Lilis, Dimitrios V Rovas .....

Paper ID 210693

Space Boundary Topology Simplification for Building Energy Performance Simulation Speed-up

Georgios Nektarios Lilis, Georgios I Giannakis, Kyriakos I Katsigarakis, Dimitrios V Rovas ......... 175

Paper ID 210932

An Approach for the Extension of OpenBIM MEP Models with Metadata Focusing on Different Use Cases

Stefan Hauer, Aurelien Bres, Rainer Partl, Michael Monsberger 
Paper ID 211120

Design and Development of Energy Efficient Re-roofing Solutions

Shahryar Habibi, Esther Obonyo, Ali M. Memari

Paper ID 211256

Sustainability Assistant - Supporting Sustainable Building Design In Context Of Integral Planning

Katharina Graf, Sebastian Ebertshäuser, Petra von Both

Paper ID 211351

Acoustic Insulation And Building Information Modeling: A Model Of Calculation For The Code

Checking In The Forecast Phase And Of Measurement The Performances.

Costantino Carlo Mastino, Roberto Baccoli, Andrea Frattolillo, Martino Marini, Chiara Salaris .......205

Paper ID 211404

Incorporating Building Performance Simulation Into a BIM Workflow

Jessica Preuss, Lukas Blattmann, Manuel Frey .....

Building physics

Paper ID 210125

Numerical And Experimental Thermal Inertia Characterization Of An Integrated Insulation Clay Hollow Block For Buildings Thermal Comfort Applications

Jean-Baptiste BOUVENOT, Vincent Jimenez, Lucas Desport, Monica Siroux.

Paper ID 210139

Heat Emissions from Buildings

Tianzhen Hong, Jing Yang, Xuan Luo

Paper ID 210161

Numeric Simulation of Heat Transfer Phenomena in Existing and Retrofitted Casement Windows

Shiva Najaf Khosravi, Ulrich Pont, Ondřej Šikula, Ardeshir Mahdavi

Paper ID 210184

New Models for Solar Protection and Dynamic Walls in Swiss Energy Calculation Standards

Gerhard Zweifel

Paper ID 210213

A Simulation Method for Measuring Building Physics Properties

Ljubomir Jankovic

Paper ID 210238

Induced Infrared Thermography: Flow Visualization of the Indoor Airflow over the Heating Surface

Qing Wu, Jing Liu, Chang-an Zhu.

Paper ID 210239

Exergy Analysis of a Residential Building in Southern Italy: Lessons for Low-Exergy Buildings and Systems

Gianpiero Evola, Vincenzo Costanzo, Luigi Marletta

Paper ID 210286

Analysis of the Energy Flexibility of Residential Buildings in the Heating and Cooling Season

Jacopo Vivian, Umberto Chiodarelli, Giuseppe Emmi, Angelo Zarrella.

Paper ID 210294

Energy Performance Modelling: Introducing the Building Early-stage Design Optimization Tool (BeDOT)

Ramón Bergel, Giovana Fantin do Amaral Silva, Max Tillberg, Angela Sasic Kalagasidis

Paper ID 210323

Environmental Sustainability and Energy Efficiency in Historical Buildings: GeoFit Project

Implementation in the Case Study of a Medieval Fortress in Perugia

Jessica Romanelli, Matteo Di Grazia, Cristina Piselli, Anna Laura Pisello, Franco Cotana.

Paper ID 210326

Influence of Sky Temperatures on Building Energy Needs

Francesco Asdrubali, Luca Evangelisti, Gianluca Grazieschi, Claudia Guattari

Paper ID 210347

Identification of a Source Location and Emission Rate in the Multi-zone Building Using

Regularization and Bayesian Approach

Xiaoran Liu, Fei Li, Jinxiang Liu, Hao Cai, Junyi Zhuang 
Paper ID 210384

A New Simplified Dynamic Algorithm for Energy Estimation in Buildings: Description and

Validation

Daniele Testi, Michele Barbieri, Eva Schito, Paolo Conti, Paolo Signoretti ..

Paper ID 210413

Experimental Validation of a Finite Difference Algorithm to Simulate Breathing Wall Components

Andrea Alongi, Adriana Angelotti, Livio Mazzarella.

Paper ID 210429

Coupled Numerical Simulations of Mitigation Measures for Local Heat Island Effect in an Urban

Neighborhood

Aytaç Kubilay, Dominique Derome, Jan Carmeliet

Paper ID 210474

Dynamic Thermal Performance Metrics for Adaptive Building Constructions

Ciril Arkar, Marco Perino.

Paper ID 210530

Modeling the Thermal Interactions between Buildings at an Urban Scale

Xuan Luo, Tianzhen Hong.

Paper ID 210560

Characterisation of Heat Losses of Zero Emission Buildings (ZEB) in Cold Climate

Johannes Georg Brozovsky, Niki Gaitani, Arild Gustavsen

Paper ID 210576

Calibration Of An Historic Masonry Building Using Measured Temperature And Heat Flux Data

Michael Gutland

Paper ID 210584

Predicting Wind-Driven Rain Catch Ratios In Building Simulation Using Machine Learning

Techniques

Ioanna Vrachimi, Daniel Costola

Paper ID 210591

Feature Assessment in Data-driven Models for Unlocking Building Energy Flexibility

Anjukan Kathirgamanathan, Mattia De Rosa, Eleni Mangina, Donal Patrick Finn.

Paper ID 210612

Numerical Modelling and Experimental Validation of Structural Laminated Glass Elements

Xavier Centelles, J.Ramon Castro, Luisa F. Cabeza.

Paper ID 210702

Generation and Simulation of Indoor Thermal Gradients: MRT for Asymmetric Radiant Heat Fluxes

Dorit Aviv, Eric Teitelbaum, Tyler Kvochick, Kipp Bradford, Forrest Meggers

Paper ID 210711

Hygro-Thermal Implications Of The Aerogel-Based Façade Insulation Layer Position And Thickness

Samira Aien, Ardeshir Mahdavi

Paper ID 210832

Generation Of Moisture Reference Years For Interstitial Condensation Risk Assessment: Influence Of The Meteorological Record Length

Michele Libralato, Giovanni Murano, Alessandra De Angelis, Onorio Saro, Vincenzo Corrado .......395

Paper ID 210853

Humidity and Temperature Variation in Building Stones: Comparing Simulation Results and

Impedance Measurements

Nayara Rodrigues Marques Sakiyama, Seyedeh Bina Mohammad Hejazi, Jürgen Frick, Frank

Lehmann, Harald Garrecht.

Paper ID 210863

Evaluation Of Ventilation Metrics For Naturally Ventilated Spaces From Flow Patterns Generated In

A Water Table Apparatus

Pooja Mundhe, Rashmin Mohan Damle, Prasad Vaidya

Paper ID 210910

A Simplified Method Of Calculating Daylight Autonomy Through Spatial Parameters For Atriums In Shopping Streets

Xinxin Li, Hong Jin, Jian Kang, Hupeng Wu. 
Paper ID 210914

Reducing Simulation Performance Gap From Hempcrete Buildings, Using Multi Objective

Optimization

Ataitiya Paterson Bana, Ljubomir Jankovic

Paper ID 210920

Impact Of Including Hemp Concrete Hysteresis On The Modelling Of Its Hygrothermal Behavior At

Wall And Room Scales

Georges Costantine, Chadi Maalouf, Tala Moussa, Guillaume Polidori, Elias kinab

Paper ID 210958

An Efficient Method To Find The Most Influential Parameters of Energy Performance Building

Envelopes

Ainagul Jumabekova, Julien Berger, Aurélie Foucquier

Paper ID 210969

$4 \pi$ Thermograms : A ProjectionTo Understand Thermal Balance

Jairo Acuña Paz y Miño, Claire Lawrence, Benoit Beckers

Paper ID 210986

A Simplified Zonal Model for The Evaluation of the Spatial Distribution of Air Temperature in Indoor Environments

Jean Pierre Campana, Matthias Schuss, Ardeshir Mahdavi, Gian Luca Morini

Paper ID 210989

Double-Skin Facades With Semi-Transparent Modules For Building Retrofit Actions: Energy And

Visual Performances

Michelangelo Scorpio, Giovanni Ciampi, Yorgos Spanodimitriou, Roberta Laffi, Antonio Rosato,

Sergio Sibilio

Paper ID 211000

Hygrothermal Performance Of A Building Across Different Climates Of India

RASHMIN MOHAN DAMLE, RAJAN RAWAL

Paper ID 211036

Are ICFs Suitable Building Envelope Solutions For Mediterranean Climatic Conditions? A Critical

Analysis Concerning Thermal Properties And Annual Energy Performances

Cristina Carpino, Roberto Bruno, Piero Bevilacqua, Natale Arcuri

Paper ID 211051

Modelling and Validation of two Heat and Mass Transfer Model of Living Walls and Evaluation of

Their Impact on the Energy Performance of a Supermarket in a Semiarid Climate

Mauricio García, Sergio Vera, Fabien Roualt, Waldo Bustamante

Paper ID 211052

Impact of Variable Air Flow Rate in Energy Smart Window Curtains, on the Total Net Heat Gain-

Analytical Solutions

Carl-Eric Hagentoft, Ali Naman Karim

Paper ID 211054

Impact Of Moisture Buffering For Improving Summer Comfort In Buildings.

Clemence Legros, Matthieu Cosnier, Monika Woloszyn, Amandine Piot, Mickael Pailha

Paper ID 211069

Assessment of the Thermal Performance of Timber Walls under Nominal or Moisture and

Temperature Dependent Properties

Maja Danovska, Giovanni Pernigotto, Paolo Baggio, Andrea Gasparella

Paper ID 211077

Coupled Heat And Moisture Transfer Simulations On Building Components Retrofitted With A

Newly Developed Aerogel-based Plaster

Stefano Fantucci, Elisa Fenoglio, Valentina Serra, Marco Perino

Paper ID 211126

Numerical Investigation of Anti-Icing Road Surfaces using Hydronic Heating Pavement- Parametric

Study

Raheb Mirzanamadi, Carl-Eric Hagentoft, Pär Johansson

Paper ID 211224

Dynamic Hygrothermal Analysis of Moisture Bridges in Mondern Masonry Constructions

Balázs Nagy 
Paper ID 211229

Comparison Of Models To Identify Thermal Characteristics Of Multi-layer Building Walls Using Inverse Methods

Manon Rendu, Jérôme Le Dréau, Patrick Salagnac, Maxime Doya, Mathilde Colmet Daâge

Paper ID 211323

Tempering The Temporary: Improving Thermal Comfort and Human Well-being in Relief Shelters

Shreejaya Tuladhar, Joelle Jahn, Holly Samuelson

Paper ID 211415

Numerical Evaluation Of Hygrothermal Performance And Mould Growth Risk Of Multi-Layer Wall

In The Hot And Humid Southern China Area

Aimin Fang, Youming Chen....

Paper ID 211419

Simulation of Energy Performance of Buildings with Innovative Aerogel Glazing Systems

Elisa Belloni, Fiorini Costanza Vittoria, Buratti Cinzia, Merli Francesca

CFD and air flow

Paper ID 210162

CFD Analysis of Indoor Air Quality in Office Rooms Equipped with Desk Fans

Hayder Alsaad, Conrad Voelker

Paper ID 210197

Optimized Window Locations of a Single Zone: for Maximizing the Wind-Driven Natural Ventilation Potential

Nari Yoon, Jung Min Han, Ali Malkawi

Paper ID 210225

Improving Prediction of Dynamic Zonal Modelling for Atrium Thermal Environment

Yanyu Lu, Yan Xiang, Gang Chen, Jing Liu

Paper ID 210297

Effects Of a Ceiling Diffuser On Diffuse Ceiling Ventilation (DCV) Performance

Alessandro Nocente, Tufan Arslan, Steinar Grynning, Francesco Goia

Paper ID 210349

Parametric Study of Air Re-entrainment within Air-Cooled Chiller Compounds

Bryony Watson, Julien de Charentenay

Paper ID 210396

Quantification Of Heat Flows Through Building Entrance Doors On A Winter Day

Daeho Kang

Paper ID 210438

On the Feasibility of CFD for Transient Airflow Simulations in Buildings

Nina Morozova, Roser Capdevila, Francesc Xavier Trias, Assensi Oliva

Paper ID 210458

Towards High-Resolution Annual Outdoor Thermal Comfort Mapping In Urban Design

Patrick Kastner, Timur Dogan

Paper ID 210476

CFD Simulation in Naturally Ventilated Multi-Purpose Sports Hall: Effects to the Basketball and Badminton Matches

M Zofron Afif, Randy Frans Fela, Sentagi Sesotya Utami, Muhammad Kholid Ridwan, Rizki

Armanto Mangkuto

Paper ID 210489

Study of High-Volume Low Speed (HVLS) Fan Blade Design on Air Flows and Velocities in a Large

Naturally-ventilated Space

Steve Kardinal Jusuf, Cheng Yang Chiam.

Paper ID 210516

LES Simulation of Oscillating Natural Ventilation Driven by Vortex Shedding in Isolated Buildings

Daniel Albuquerque, Mats Sandberg, Paul Linden, Guilherme Carrilho da Graça 
Paper ID 210532

Comparative Study on Pollution-block Performance of Ceiling-supply Air Curtain System for Commercial Building Entrance

Ran Duan, Jiagen Liu.

Paper ID 210589

Optimization of Workload Distribution of Data Centers Based on a Self-Learning In Situ Adaptive Tabulation Model

Xu Han, Wei Tian, Wangda Zuo, James W. VanGilder

Paper ID 210590

Effect Of The Location Of An Active Chilled Beam On Thermal Comfort And Energy Efficiency: An Optimization Study

Nikhilesh Ghanta, Barry Coflan, Leon Glicksman ..

Paper ID 210646

The Influence Of Solar-Induced Thermal Effect On Outdoor Ventilation Within Generic Urban

Neighbourhood.

Guoxing Chen, Li Rong, Guoqiang Zhang

Paper ID 210660

A Study on the Effectiveness of Wind-Induced Natural Ventilation and Shading Analysis on a

Residential Apartment Typology

Tanvi Praskash Medshinge, Prasad Vaidya, Monisha Edwina Royan

Paper ID 210665

Assessment Of Venturi Effect For Enhancing Natural Ventilation In Composite Climate Of India

Ankit Shukla, Vineet Sharma, Neeraj Kapoor, Ashish Kumar.

Paper ID 210695

Design Charts To Assist On The Sizing Of Natural Ventilation For Cooling Residential Apartments In India.

Luciano Caruggi de Faria, Malcolm J Cook, Dennis Loveday, Charalampos Angelopoulos, Yash

Shukla, Rajan Rawal, Sanyogita Manu, Deepta Mishra, Jayamin Patel, Saranya Anbarasu

Paper ID 210714

Towards Development and Validation of a Simplified Infiltration Model for Commercial Buildings

Adam Douglas Wills, Justin Berquist, Iain A Macdonald

Paper ID 210745

Effective Turf Planting Layout for Heat Mitigation in Schoolyards

Noriko Umemiya

Paper ID 210883

Analysis of airflow and thermal characteristics in Slim Double Skin Facade (SDSF) using CFD

Haneul Choi, Kyungmo Kang, Youngsub An, Eunjin Kim, Yungyu Lee, Taeyeon Kim

Paper ID 210893

Simulation Analysis of Using Natural Ventilation Special Architectural Design in an Attic of Building Integrated with Photovoltaic Modules (BIPV)

Arash Zarmehr, Joseph T. Kider Jr.

Paper ID 210901

Simulation Study Of Individual Thermal Comfort With The Integrated Personalized Fan And VAV System

Siliang Lu, Erica Cochran Hameen.

Paper ID 210906

Patterning Airflow: Qualitative Analysis and Design for Thermal Comfort

Christine Yogiaman, Oindrila Ghosh, Kenneth Joeseph Tracy, Pablo Valdivia y Alvarado

Paper ID 210960

Effect of Staff Number on the Bacteria Contamination in Operating Rooms with Temperature

Controlled Airflow Ventilation and Turbulent Mixing Ventilation

Cong Wang, Parastoo Sadeghian, Sasan Sadrizadeh

Paper ID 211040

Design Optimisation Of Façade-Integrated Photobioreactors Using CFD Simulation

Jake Haskell, Matthias Frechen, Timo Sengewald .... 
Paper ID 211142

Impact Of Micro-Climate On Ventilation Availability And Indoor Thermal Comfort

Sushanth S

Paper ID 211149

Numerical Analysis Of Micro-ventilation System In A Wine Cellar

Enrica Santolini, Alberto Barbaresi, Daniele Torreggiani, Patrizia Tassinari

Paper ID 211227

The Effect of Urban Geometry on Microclimate

Eleni Liapopoulou, Yeonsook Heo

Paper ID 211281

Ventilation Efficiency Of Push-Pull Ventilation Systems In Residential Buildings - CFD Simulation

And Validation Of The Model With Measurements In A Research Apartment

Markus Wirnsberger, Marcel Küfner, Harald Krause

Paper ID 211401

Numerical Study on Safety Factor for Deflection Modulus of the Non-recirculating and Recirculating

Air curtain

Sihwan LEE

Paper ID 211422

Optimal Design Of An Indoor Environment Using An RNG K-E Adjoint Turbulence Model

Xingwang Zhao, Qingyan Chen

Commissioning and control

Paper ID 210146

Commissioning of HVAC Systems in a Campus Building with Regard to Indoor Environment and Energy Performance

Chen Zhang, Adam Iversen, Anda Senberga, Andras Cedl, Liena Krastina, Vilija Matuleviciute,

Evangelia Loukou, Mingzhe Liu, Anna Marszal.

Paper ID 210148

Flexibility Characterization of a Residential Neighbourhood With Water-to-water Heat Pumps Using

Model Predictive Control

Frédéric Amblard, Ramanunni, Parakkal Menon, Jessen Page.

Paper ID 210200

Dynamic Energy Model-Based Automatic Building Performance Testing for Continuous

Commissioning

Muhyiddine Jradi, Na Liu, Aslak Johansen, Krzysztof Arendt, Claudio Giovanni Mattera, Mikkel

Baun Kjærgaard, Christian Veje, Bo Nørregaard Jørgensen

Paper ID 210226

State Estimators Applied To A White-box Geothermal Borefield Controller Model

Iago Cupeiro Figueroa, Ján Drgoňa, Lieve Helsen..

Paper ID 210251

On Formulation and Training of Grey-box Thermal Model for Low-rise Residential Buildings

Zixiao Shi, Guy Newsham, Ajit Pardasani, H. Burak Gunay

Paper ID 210308

Development and Analysis of Simplified Control-oriented Models for a Group of Institutional Offices

Jayson Bursill, William O'Brien, Ian Beausoleil-Morrison

Paper ID 210311

Model-based Fault Detection and Diagnosis for HVAC Systems Using Convolutional Neural Network

Shohei Miyata, Yasunori Akashi, Jongyeon Lim, Yasuhiro Kuwahara, Katsuhiko Tanaka.

Paper ID 210340

Study on Efficient Heat Interchange Control in District Heating and Cooling System with Multiple

Sub-plants

HISATAKA KITORA, Yasunori Akashi, Jongyeon Lim 
Paper ID 210609

Advanced Control Strategies For The Modulation Of Solar Radiation In Buildings: MPC-Enhanced Rule-Based Control

Marco Savino Piscitelli, Silvio Brandi, Giovanni Gennaro, Alfonso Capozzoli, Fabio Favoino,

Valentina Serra

Paper ID 210699

Use Of Multidimensional Scaling For Fault Detection Or Monitoring Support In A Continuous

Commissioning

Hugo Geoffroy, Julien Berger, Benoit Colange, Sylvain Lespinats, Denys Dutykh, Catherine Buhe,

Gérard Sauce.

Paper ID 210722

Verification of Control Sequences within OpenBuildingControl

Michael Wetter, Antoine Gautier, Milica Grahovac, Jianjun $\mathrm{Hu}$

Paper ID 210945

A Diagnostic Bayesian Network Method To Diagnose Building Energy Performance

Arie Taal, Laure Itard, Wim Zeiler

Paper ID 210992

Applying Machine Learning to Automate Calibration for Model Predictive Control of Building

Energy Systems

Thomas Storek, Asad Esmailzadeh, Phlipp Mehrfeld, Markus Schumacher, Marc Baranski, Dirk

Müller ......

Paper ID 211001

Characterisation and Quantification of Energy Flexibility in the Residential Sector

Adamantios Bampoulas, Mohammad Saffari, Fabiano Pallonetto, Mattia De Rosa, Eleni Mangina,

Donal Finn

Paper ID 211059

Assessing the Impact of Direct Evaporative Control Algorithms in Mixed-mode Building

Charalampos Angelopoulos, Malcolm J Cook, Yash Shukla, Efi Spentzou, Rajan Rawal, Luciano

Caruggi-De-Fari, Dennis Loveday, Sanyogita Manu, Deepta Mishra, Jayamin Patel.

Paper ID 211222

Coupling of Modelica Domestic Hot Water Simulation Model with Controller

Elisa Van Kenhove, Lien De Backer, Marc Delghust, Jelle Laverge

Paper ID 211335

Energy Savings of Occupancy-Based Controls in Office Buildings

Weimin Wang, Jian Zhang, Brambley Michael, Benjamin Futrell

Paper ID 211356

Coupling Building System and Power Grid Models to Simulate the Building-to-Grid Integration

Yangyang Fu, Sen Huang, Yuan Liu, Thomas McDermott, Draguna Vrabie, Wangda Zuo

Paper ID 211358

Impact of Realistic Controls on Building Energy Consumption and Comfort

Rohini Brahme, Aswath Mukundan, Rakesh Goel.

Paper ID 211427

A Simplified Building Controls Environment with a Reinforcement Learning Application

Vasken Dermardiros, Scott Bucking, Andreas K. Athienitis

Daylighting and lighting

Paper ID 210105

Building Climate-based Daylighting Models Based On One-time Field Measurements

Geraldine Quek, John Alstan Jakubiec

Paper ID 210218

Lighting Design For Psychophysical Wellbeing: Tools And Investigation Methods.

Sveva Mazza dè Piccioli, Gianfranco Cellai, Simone Secchi

Paper ID 210267

Fast Climate-Based Glare Analysis and Spatial Mapping

Nathaniel L Jones 
Paper ID 210307

Modeling Daylight in Adjacent Spaces of the Courtyard under Clear Sky Conditions

Maitha Bin Dalmouk, Khaled A. Al-Sallal.

Paper ID 210369

Predicting Annual Equirectangular Panoramic Luminance Maps Using Deep Neural Networks

Yue Liu, Alex Colburn, Mehlika Inanici

Paper ID 210371

Sensitivity Analysis on the Impact of Controlling Decisions on Daylight and Energy Simulations

Sahar Abdelwahab, Sergio Altomonte, Peter Rutherford, Mohammed Mayhoub.

Paper ID 210378

Simulating The Performance Of Daylight-Linked Control Systems

Laura Bellia, Francesca Fragliasso

Paper ID 210392

Lighting Effects on Human Behaviour and Movements: a Correlation between Space Syntax and

Modelling Index in a Museum Environment

Giacomo Salvadori, Davide Lista, Francesco Leccese, Carla Balocco

Paper ID 210483

A Methodology To Model The Performance Of a Dynamic Mirror Light-shelf Based on Solar Radiant Flux Impinging on the Window

Aris Tsangrassoulis, Lambros Doulos, Antonios Kontadakis, Aikaterini Drakou.

Paper ID 210494

A Novel Method For Daylight Harvesting Optimization Based On Lighting Simulation And DataDriven Optimal Control

Tullio de Rubeis, Niko Gentile, Francesco Smarra, Alessandro D'Innocenzo, Dario Ambrosini,

Domenica Paoletti....

Paper ID 210503

Effect of Facade Thickness on Daylight Performance in a Reference Office Building

Rizki A. Mangkuto, Randy Frans Fela, Sentagi Sesotya Utami

Paper ID 210585

Tri-stimulus Color Accuracy in Image-based Sky Models: Simulating the Impact of Color

Distributions throughout the Sky Dome on Daylit Interiors with Different Orientations

Mehlika Inanici.

Paper ID 210599

A Design Method for Complex Fenestration Systems Using Forward Raytracing

Islam Ayman Mashaly, Veronica Garcia-Hansen, Gillian Isoardi, Marianella Chamorro-Koc

Paper ID 210626

Evaluation of Energy Savings of Daylight-Linked Lighting Control Strategies Using Different Sky

Distribution Models

Wenqiang CHEN, Danny H W LI, Shuyang LI.

Paper ID 210677

The Effects of Orientation, Window Size, and Lighting Control to Climate-Based Daylight

Performance and Lighting Energy Demand on Buildings in Tropical Area

Randy Frans Fela, Sentagi Sesotya Utami, Rizki Armanto Mangkuto, Dwi Joko Suroso

Paper ID 210728

Instantaneous and Long-term Lighting Design Metrics for Higher Education Buildings in a Tropical

Climate

Zhe Kong, J.Alstan Jackubiec

Paper ID 210742

A Methodology To Simulate Annual Blind Use In Large Open Plan Offices

Kieu Pham, Ayman Wagdy, Gillian Isoardi, Alicia Allan, Veronica Garcia Hansen.

Paper ID 210755

A New Framework for Evaluating Views throughout Open Plan Work Spaces

Irmak Turan, Christoph Reinhart, Michael Kocher 
Paper ID 210761

Dynamic Cubic Illuminance: An Example Of Application Of A New Paradigm For Daylight Analysis In An Ancient Pompeian Domus

Juan Manuel Monteoliva, Francesca Fragliasso, Laura Bellia, Andrea Pattini

Paper ID 210785

Climate-Based Daylighting Metrics Assessment to Select among Optimum Energy Efficient

Windows' Shading Devices Solutions: case study of an office in a hot climate

Ali Alajmi, Faris Abaalkhail, Adnan Alanzi

Paper ID 210800

Daylight Simulation and Compliance: Reliability of Climate Data Solar Radiation Models

Eleonora Brembilla, John Mardaljevic, Anastasia Mylona

Paper ID 210810

Aperture-Based Daylight Modelling: Introducing the 'View Lumen'

John Mardaljevic

Paper ID 210843

Adapting the Residential Daylight Score for Arid, Hot, and Humid Climates

Ye Chan Park, Timur Dogan

Paper ID 210866

A Method for Optimizing Facades Design for Enhancing Daylight Distribution in Exhibition Spaces

Fatma Fathy, Yasser Mansour, Hanan Sabry, Mostafa Refat, Ayman Wagdy

Paper ID 210898

Subjective and Measured Evidence for Residential Lighting Metrics in the Tropics

J. Alstan Jakubiec, Thanyalak Srisamranrungruang, Zhe Kong, Geraldine Quek, Riccardo Talami 1151

Paper ID 210912

Evaluation of Daylight Performance of the New Workshop Building at CEPT University, Ahmedabad

Vasudha Sunger, Prasad Vaidya

Paper ID 210928

Model Evaluation and Development for Global Luminous Efficacy Models through On-Site

Measurement and Optimization Techniques

Cong Thanh Do, Hui Shen, Ying-Chieh Chan, Xiaoyu Liu

Paper ID 210943

Estimation of Point Daylight Factor (PDF) Average Daylight Factor (ADF) and Vertical Daylight Factor (VDF) under various CIE standard obstructed Skies

Shuyang LI, Danny H W LI, Wenqiang CHEN

Paper ID 210951

Simulating Daylighting and Energy Demand for Lighting of Buildings with Different Models and Programs: Analysis of Influencing Factors and Comparison of Results

Anna Pellegrino, Valerio Roberto Maria Lo Verso, Argun Paragamyan

Paper ID 211158

Spectral Rendering with Daylight: A Comparison of Two Spectral Daylight Simulation Platforms

Priji Balakrishnan, Alstan J.Jakubiec.

Paper ID 211175

Color Heterogeneity Of Building Surfaces: Lean Image Processing Approach For Visible Reflectance Characterization Performance

Juan Diego Blanco Cadena, Alberto Speroni, Andrea Giovanni Mainini, Tiziana Poli

Paper ID 211185

The Impact Of Window Systems On Daylighting Performance, Visual Comfort And Energy

Efficiency In Patient Rooms

Nazanin Eisazadeh, Karen Allacker, Frank De Troyer

Paper ID 211194

Dynamic Balancing Between Personalized Daylight Preferences And Lighting Energy Use:

Implementation Of A Multi-Objective Optimization Framework

Jie Xiong, Thanos Tzempelikos, Panagiota Karava, Ilias Bilionis 
Paper ID 211230

An Alternative Method for the Assessment of the Typical Lighting Energy Numeric Indicator for Different Outdoor Illuminance Conditions

Benedetta Mattoni, Alessandro Mangione, Laura Pompei, Fabio Bisegna, Domenico Iatauro,

Francesco Spinelli, Michele Zinzi

Paper ID 211259

Multi Objective Optimization on Daylight Control System's Qualitative and Quantitative Performance

Yun Kyu Yi, Keunhyuk Jang.

Paper ID 211290

The Case for Occupant-Centric Daylight Analytics: a Comparison of Horizontal Illumination and Immersive View

Siobhan Francois Rockcastle, Maria Lovisa Amundadottir, Marilyne Andresen

Paper ID 211380

Generative Design Approaches to Daylight in MURBs

Terri Peters, Jacob Wolf, Brady Peters, Ted Kesik

Developments in simulation

Paper ID 210108

A Frequency Domain Methodology for Design and Control of Radiant Floor Systems

Ali Saberi Derakhtenjani, Andreas Athienitis, Katherine D'Avignon.

Paper ID 210135

Cockroaches 0.0 Beta: Exploring The Novel Building Performance Simulation Domain Of Pest

Modelling Through A Literature Review

Clarice Bleil de Souza, Pieter de Wilde

Paper ID 210182

Application Of A Method Of 1-D Equivalent Wall To Multidimensional Geometries: Impact On Building Energy Performance

Julien Quinten, Véronique Feldheim

Paper ID 210214

Determination Of A Short Simulation Sequence For The Multi-Criteria Optimization Of Buildings: A Case Study

Hasan Sayegh, Gilles Fraisse, Antoine Leconte, Etienne Wurtz, Ophélie Ouvrier Bonaz, Simon

Rouchier.

Paper ID 210222

A Specific Building Simulation Tool For The Design And Evaluation Of Innovative Fenestration

Systems And Their Control

Bruno Bueno, Abel Sepúlveda

Paper ID 210252

A Fast Response Performance Simulation Screening Tool In Support Of Early Stage Building Design

Marco Picco, Marco Marengo

Paper ID 210257

Unlocking Potentials of Building Energy Systems' Operational Efficiency: Application of Digital

Twin Design for HVAC systems

Christian Vering, Philipp Mehrfeld, Markus Nürenberg, Daniel Coakley, Moritz Lauster, Dirk Müller 1304

Paper ID 210265

Updated OpenStudio(OS) Small and Medium Office Prototype Models

Piljae Im, Joshua R. New, Yeonjin Bae

Paper ID 210318

Effect of Simulation methodology on variable efficiency of Bi-directional Heat Recovery Ventilator.

Younhee Choi, Beungyong Park, Doosam Song .....

Paper ID 210375

Real-Time Experimental Connection of an EnergyPlus Building Model with a Real Water-To-Water

Heat Pump Through Functional Mock-Up Interface

Paolo Taddeo, Joana Ortiz, Ivan Bellanco, Elena Fuentes, Jaume Salom 
Paper ID 210403

Design Guidance From A Data-Driven LCA-Based Design Method And Tool Prototype

Thomas Jusselme, Pedro Antunes Fernandes, Emmanuel Rey, Marilyne Andersen

Paper ID 210426

Near-Roof Air Temperatures: Modelling the Implications for HVAC Performance and Cool Roofs

Alan Green, Laia Ledo Gomis, Riccardo Paolini, Shamila Haddad, Georgios Kokogiannakis, Paul

Cooper, Zhenjun Ma, Buyung Kosasih, Mattheos Santamouris

Paper ID 210433

A Generic Micro-Cogeneration Model Adapted To Various Technologies For Building Energy

Simulation Purpose

Romain Bonabe de Rougé, Pierre Picard, Pascal Stabat, Dominique Marchio.

Paper ID 210473

Modelling the Dynamic Thermal Response of Turbulent Fluid Flow Through Pipelines

Saleh Salavati Meibodi, Simon Rees, Dongmin Yang.

Paper ID 210491

Distributed Co-Simulation Applied To Urban Scale Energy Systems Design

Pablo Puerto, Jessen Page, Bruno Ladevie, Jakob Rager...

Paper ID 210517

Optimisation Of Controller Parameters For Adaptive Building Envelopes Through A Co-Simulation Interface: A Case Study

Esther Borkowski, Mattia Donato, Giovanni Zemella, Dimitrios Rovas, Rokia Raslan

Paper ID 210522

An Archaeological Excursion into Historic Simulation Tools

Jon William Hand .....

Paper ID 210541

Time-series Decomposition Approach For Simulating Electricity Demand Profile

Sandhya Patidar, David Jenkins, Andrew Peacock, Peter McCallum.

Paper ID 210542

Surrogate Model Development for Naturally Ventilated Office Buildings

Marcelo Salles Olinger, Ana Paula Melo, Letícia Oliveira Neves, Roberto Lamberts

Paper ID 210583

Quantifying Occupancy-adaptive Building Operations

Mohamed Ouf, William O'Brien, Burak Gunay, Afaf Azzouz, Philip Richard, Giuliano Todesco.. 1404

Paper ID 210614

Reinforcement Learning Control Algorithm for HVAC Retrofitting: Application to a Supermarket

Building Model by Dynamic Simulation

Antonio Mastropietro, Fabio Castiglione, Stefano Ballesio, Enrico Fabrizio.

Paper ID 210617

A Critical Evaluation of Radiance as a Tool for Calculating Radiation View Factors.

Sarith Subramaniam, Sabine Hoffmann

Paper ID 210673

Empirical Validation Of A Data-Driven Heating Demand Simulation With Error Correction Methods

Felix Bünning, Andrew Bollinger, Philipp Heer, Roy Smith, John Lygeros.

Paper ID 210752

Development And Validation Of A Low-Order Thermal Model For Building Behavior

Julie Cousin, Jessica Leo, Valentin Gavan, Chloe Duchayne.

Paper ID 210762

Efficient Numerical Method For Long Term Simulation Of Insulated Wall

Madina Abdykarim, Julien Berger, Amen Agbossou, Denys Dutykh

Paper ID 210779

Diagnoses Of Building Thermal Characteristics By Parameter Identification And Manual Inspection.

Tatsuya Ohira, Tatsuo Nagai

Paper ID 210798

Modeling of Thermal and Optical Processes in Translucent Structures Filled with PCM Layer Using

Moving Mushy Volume Approach

Tomasz Kułakowski, Dariusz Heim 
Paper ID 210819

Simulating the Power Load Curve at the District Scale - Introduction of a Dedicated Platform

Loïc Frayssinet, Lucie Merlier, Damien David, Jean-Jacques Roux, Frédéric Kuznik.

Paper ID 210834

Comparison Of Simulation Results For A Reference Office Building - Analysis Of Deviations For Different BES Tools

Mara Magni, Fabian Ochs, Paolo Bonato, Matteo D’Antoni, David Geisler-Moroder, Samuel de Vries,

Roel Loonen, Alessandro Maccarini, Alireza Afshari, Toni Calabrese

Paper ID 210848

Simulation-Based Design and Optimization of a Stand-Alone Power and Energy System for the High

Arctic

Stéphanie Breton, Martin Kegel, Gisele Amow.

Paper ID 210860

A Modelling Approach to Reduce the Simulation Time of Building Stock Models

Rana Mahmoud, Eline Himpe, Marc Delghust, Jelle Laverge

Paper ID 210941

Cellular Automata Simulations of Three-dimensional Building Heat Loss Field

Purvesh Bharadwaj, Ljubomir Jankovic

Paper ID 210956

Comparison and Verification of the Simulation Results of DeST Based on ASHARE Standard 1402014

Yue Jiang, Xing Shi, Xin Zhou, Xing Jin, Jingjing An, Da Yan

Paper ID 211032

Building Energy Prediction for Early Design Stage Decision Support: A Review of Data-driven

Techniques

Aman Batish, Avlokita Agrawal

Paper ID 211087

Twenty Years of Building Performance Analysis Trends: A Topic Modeling Analysis of the Bldg-Sim Email List Archive

Clayton Miller, Matias Quintana, Jason Glazer

Paper ID 211130

Quantifying Resilience of Building Facades: Moisture and Mold Risks under Future Climate Stresses

Pamela Cabrera, Holly Samuelson, Margaret Kurth.

Paper ID 211176

Algorithms for Modeling Multiple Air Handling Units Serving the Same Zone in EnergyPlus

Michael J. Witte

Paper ID 211187

Using Python to Automate the Preparation and Execution of Thousands of Daylighting and Glare

Simulations on a Cloud Parallel Computing environment for Time-efficient Simulations

Rania Labib, Juan-Carlos Baltazar

Paper ID 211214

Towards a Systemic Approach For Supporting Design Process Of Deep Renovation Packages Based

On Prefabricated Façade Technologies

Roberta Pernetti, Riccardo Pinotti, Babich Francesco, Lollini Roberto.

Paper ID 211232

Adaptive Sampling For Building Simulation Surrogate Model Derivation Using The LOLA-Voronoi

Algorithm

Paul Willem Westermann, Ralph Evins

Paper ID 211236

Insight Into Predictive Models: On The Joint Use Of Clustering And Classification By Association (CBA) On Building Time Series

Paul Westermann, Johanna Braun, Eamon Murphy, Joel Grieco, Ralph Evins

Paper ID 211313

Use of EnergyPlus as an Analysis Tool to Test the Influence of Constructional Parameters on Mold

Growth Factors

Vinicius de Castro Silveira, Fernando Simon Westphal.. 
Education

Paper ID 210106

Teaching Building Performance Simulations by using a Control Method

Niko Gentile, Jouri Kanters, Henrik Davidsson.

Paper ID 210110

Use of EQuest In The Design And Analysis of HVAC Systems: Lessons From Building Engineering Courses

Radu Zmeureanu.

Paper ID 210117

Integrating Building Physics And Performance Simulation In Architectural Curricula: A Collaborative Effort

Christiane Berger, Ardeshir Mahdavi

Paper ID 210230

Evaluation Of The Use Of Building Performance Simulation For Architectural Design Studio Projects

Veronica Soebarto.

Paper ID 210579

Learning Performance-driven Design. Students Approach Integrating Urban Form Studies and

Building Performance Analysis

Francesco De Luca.

Paper ID 210856

Early Design Decision-Making Framework Based on Multi-Objective Building Performance

Simulation Incorporating Energy, Carbon Footprint and Cost

Allison Bernett, Timur Dogan

Paper ID 210861

Integrating Analog Design Techniques and Building Performance Simulation - From Intuitiveness to

Counter-Intuitiveness in Architectural Design Process

Jihun Kim

Paper ID 210887

Measuring the Effectiveness of Simulation-Based Education in the Performance-Based Design Studio

Khaled Aly Tarabieh, Nouran El Begermy

Energy storage

Paper ID 210236

Numerical And Experimental Study On Thermoelectric Radiant Panel Heating Operation

Hansol Lim, Joon-Young Park, Yoo-Suk Byon, Yong-Kwon Kang, Jae-Weon Jeong.....

Paper ID 210316

Experimental And Numerical Investigations On Optimal Phase Change Material Melting Temperature Utilized Either Alone Or With Night Ventilation

Ebrahim Solgi, Ruwan Fernando, Zahra Hamedani

Paper ID 210358

Natural Ventilation Control to Enhance the Performance of Building Envelope with Integrated Phase

Change Material for Passive Applications in Summer

Cristina Piselli, Alvaro de Gracia, Mohit Prabhakar, Anna Laura Pisello, Luisa F. Cabeza

Paper ID 210368

Nationwide Evaluation of Potential Energy Savings and Payback of Integrated Building and Battery

Energy Storage System through Model Predictive Controls

Hannah Charlene Fontenot, Bing Dong, Karen Aradillaz, Gabriela Pineda, Zhaoxuan Li, Tianhui Jiang.......

Paper ID 210463

Simplifying The Parametrization Of The Extended Kinetic Battery Model To Calculate Voltage,

Current, And A Variable Load Dependent Capacity

Christoph Banhardt, Christoph Nytsch-Geusen, Daniel Wolf.

Paper ID 210464

Performance Analysis and Control Strategies to Enhance Free Cooling with an Active PCM-Heat

Exchanger

Navid Morovat, Jose Agustín Candanedo, Andreas K Athienitis 
Paper ID 210505

Quantifying the Value of Unitary Thermal Storage Systems (UTSS) - A Modeling Study

Karl William Heine, Paulo Cesar Tabares Velasco, Michael Deru, Ben Polly.

Paper ID 210566

Numerical Analysis and Evaluation of Large-Scale Hot Water Tanks and Pits in District Heating Systems

Abdulrahman Dahash, Michele Michele Bianchi Janetti, Fabian Ochs....

Paper ID 210618

Ventilation Pre-heating Effectiveness of a PCM Solar Air Collector with Ventilated Window System

Yue Hu, Per Kvols Heiselberg.

Paper ID 210841

Simulation-based Design Optimization of Houses with Low Grid Dependency

Zahra Mohammadi, Pieter-Jan Hoes, Jan Hensen

Paper ID 210968

Demand Controlled Ventilation for Electric Demand Side Flexibility

Anthony Vautrin, Sebastian Troitzsch, Srikkanth Ramachandran, Thomas Hamacher.

Paper ID 211031

Strategies For The Reduction Of Electricity Consumptions In Heat Pumps: The Role Of The Thermal Inertia In Buildings Equipped With Radiant Systems

Natale Arcuri, Roberto Bruno, Piero Bevilacqua, Cristina Carpino

Paper ID 211261

Controlled Natural Ventilation Coupled With Passive PCM System To Improve The Cooling Energy Performance In Office Buildings

Mohammad Saffari, Mohit Prabhakar, Alvaro de Gracia, Eleni Mangina, Donal P. Finn, Luisa F.

Cabeza

Paper ID 211304

The Effect of Fuel and Storage System Price on the Economic Analysis of Off-grid Renewable

Energy Systems

Azin Rahimzadeh, Ralph Evins

Paper ID 211375

Charging and Discharging a Coaxial Borehole Heat Exchanger as a battery

Hongshan Guo, Forrest Meggers

Heating, Ventilation and Air Conditioning (HVAC)

Paper ID 210165

Study on Thermal Isolation Efficiency for Air knife Applied to Opening between Two Temperature

Difference Space

Yu-Lieh Wu, Pon-Shian Hsu, Jun-Tso Chiu

Paper ID 210253

Heating Of Staircases In High-Rise Buildings

Dmitry Ivanov, Olga Yakimchuk, Ivan Pastukhov

Paper ID 210292

Simulation Model for Minimal Invasive Refurbishment Approaches Through Prefabricated

Multifunctional Radiant Heating Façade Elements

Michael Bayer, Markus Karnutsch, Michael Grobbauer, Matthias Gnigler, Markus Leeb

Paper ID 210298

Analysis Of A Double Source Heat Pump System In A Historical Building

Angelo Zarrella, Roberto Zecchin, Francesco De Rossi, Giuseppe Emmi, Michele De Carli, Laura

Carnieletto.

Paper ID 210315

Sensitivity Of Design Parameters On Energy, System And Comfort Performances For Radiant Cooled Office Buildings In The Tropics

Riccardo Talami, J. Alstan Jakubiec

Paper ID 210362

Efficiency Increase in Low Temperature Networks with Decentralised Feed Pumps

Christoph Stettler, Artem Sotnikov. 
Paper ID 210372

ANN Based Optimized AHU Discharge Air Temperature Control of Conventional VAV System for Minimized Cooling Energy in an Office Building

Jong Man Lee, Won Hee Kang, Kwang Ho Lee.

Paper ID 210395

Study Of The Heat Recovery Potential Of Water-to-air Heat Pumps In A Closed-loop System In

Office Buildings

Juan Francisco Belmonte, Minerva Diaz-Heras, Jose Domingo Moya, Juan Ignacio Corcoles, Jose

Antonio Almendros-Ibañez, Antonio Molina.

Paper ID 210412

Competence of a Spray Passive Down-draft Evaporative Cooling (PDEC) System For Space Cooling

Daeho Kang, Richard K. Strand

Paper ID 210416

Building Energy Modelling for Development of Active Facade Panel with Solar generation and Thermoelectric Air-conditioning Unit

Vojtěch Zavřel, Tomáš Matuška, Vladimír Zmrhal

Paper ID 210453

High Resolution Model-based HVAC Fault Detection and Diagnosis (FDD) Considering Building Operation Uncertainty

Yifu Shi, Godfried Augenbroe.

Paper ID 210498

A Petri Net Model Of Heat Pump Operating Faults

Minh Toan VO, Emmanuel BOZONNET, Charles PELE

Paper ID 210524

Temperature And Thermal Comfort In Office Spaces: Measurements Vs. Simulations

Nicola Lolli, Johannes Brozovsky, Alessandro Nocente, Steinar Grynning

Paper ID 210582

Enhancing the Implementation of a First-order Equivalent Thermal Parameter Model to Enable

Accurate and Robust Building Thermal Response Prediction

Kathryn Hinkelman, Sen Huang, Jing Wang, Jianming Lian, Wangda Zuo

Paper ID 210611

Development and Implementation of a Reversible Variable Speed Heat Pump Model for Model

Predictive Control Strategies

Riccardo Toffanin, Thibault Péan, Joana Ortiz, Jaume Salom

Paper ID 210629

Coupled Building and System Simulations for Detection and Diagnosis of High District Heating

Return Temperatures

Aurelien Bres, Christian Johansson, Roman Geyer, Paolo Leoni, Johan Sjögren

Paper ID 210637

A facade-integrated Multi-Source Heat Pump in Combination with a Ventilation System for Heating and Cooling

Dietmar Siegele, Fabian Ochs.

Paper ID 210652

Multi-Scale Simulation Thermo-Chemical District Network

Muhannad delwati, Dirk saelens, Philipp geyer.

Paper ID 210667

Development of Energy Efficiency Estimation Method for Variable Refrigerant Flow Air-

Conditioning System with Unbalanced Heat Load Operation

Masato Miyata, Koji Kurotori, Napoleon Enteria, Hideki Yamaguchi, Takao Sawachi, Yasuo

Kuwasawa.

Paper ID 210697

Comparison of the Floor and Infrared Radiant Heating System in Large-Space Buildings

Lizhi Jia, Junjie Liu, Wu Xiao, Haiqiao Zhang

Paper ID 210705

INDIGO Project A Simulation Based Approach To Support District Cooling Design And Operation

Andrea Costa, Raymond Sterling 
Paper ID 210721

The Impact Of Plants On HVAC System Performance In Cold Climate: A Parametric Study

Timothé Lalonde, Marie-Hélène Talbot, Danielle Monfet

Paper ID 210756

Numerical Study of Heat Transfer in an Air-to-Air Heat Exchanger Integrated with a Thermoelectric Heat Pump

Seong-Yong Cheon, Hye-Won Dong, Yong-Kwon Kang, Soo-Jin Lee, Jae-Weon Jeong

Paper ID 210758

Demand-Side-Management Potentials for Heat Pumps in Residential Buildings

Steffen Bechtel, Frank Scholzen, Sasan Rafii-Tabrizi, Jean-Regis Hadji-Minaglou

Paper ID 210780

Using Modelica to Assess the Resilience of a Heat Supply System

Anne Senkel, Gerhard Schmitz

Paper ID 210828

Numerical Simulation of a Magnetocaloric Heat Pump for Domestic Hot Water Production in

Residential Buildings

Hicham Johra, Konstantin Filonenko, Anna Marszal-Pomianowska, Per Heiselberg, Christian Veje,

Stefano Dall'Olio, Kurt Engelbrecht, Christian Bahl

Paper ID 210847

Simulation and Coordinated Control of Radiant and Convective Cooling Systems with Ventilation for Multi-Zone Buildings

Christopher Laughman, Christopher Mackey, Scott A. Bortoff, Hongtao Qiao .....

Paper ID 210851

Thermal Modelling Of Earth Air Heat Exchanger (EAHE) And Analyse Of Health Risk

Geoffroy Chardome, Véronique Feldheim

Paper ID 210870

Modeling and Simulation of a Heating Mini-Grid for a Block of Buildings

Konstantin Filonenko, Krzysztof Arendt, Muhyiddine Jradi, Søren Andersen, Christian Veje

Paper ID 210886

Dehumidification Performance Improvement of a Cross flow type Liquid Desiccant Dehumidifier by Dehumidifier Dimensions Modification

Hye-Jin Cho, Beom-Jun Kim, Soo-Jin Lee, Jae-Weon Jeong

Paper ID 210947

Energy Saving Potentials of Organic Rankine Cycle in a Desiccant-assisted Ventilation System for Residential Buildings

Hye-Won Dong, Hansol Lim, Hye-Jin Cho, Yoo-Suk Byon, Jae-Weon Jeong

Paper ID 210962

Experimental and Theoretical Energy Analysis of Two Types of Radiant Floor Heating Systems

Giulia Alessio, Angelo Zarrella, Pierfrancesco Brunello, Fabrizio Pulga, Marco Della Bianca, Michele

De Carli.

Paper ID 210965

Combination Of A Wood-Pellet Boiler-Stove With Other Conventional And Renewable Heating

System For Space Heating And Domestic Hot Water Within A Passive House In Belgium

Van Long Lê, Arnaud Candaele, Kévin Siau, Jean-Dominique Thomassin, Thomas Duquesne, Olivier

Fontaine de Ghélin

Paper ID 210980

Preheating Cold Supply Air To Mechanical Balanced Ventilation Using Wastewater Or Passive

Geothermal Energy

Behrouz Nourozi, Qian Wang, Adnan Ploskic

Paper ID 211011

Energy Consumption Evaluation and Optimization of Radiant and Personalized Cooling in Hot-

Humid and Dry Climatic Zone

Crosby Paul, Basil T Kochupurackal, S. Rajkumar

Paper ID 211049

Parametric Study Of The Thermal Performance Of A Single-family House Equipped With An Airflow Window Integrating A Heated Glazing

Madi Kabore, Ghislain Michaux, Jérome Ledreau, Patrick Salagnac, Rémy Greffet. 
Paper ID 211079

Maximizing The Use Of Ductless Mini-split Systems In Residential Buildings With Existing HVAC Equipment In EnergyPlus.

Zhihong Pang, Yan Chen, Cheryn Metzger, Christopher Dymond, Zheng O'Neill, Jian Zhang ......2026

Paper ID 211089

Experimental Testing and Modelling of a Variable Capacity Air-to-air Heat Pump in Cooling Mode

Gregor Strugala, Michaël Kummert, Martin Kegel

Paper ID 211096

CFD Evaluation of Experimental Measurements of Oscillating Mist Fan Cooling in a Large Indoor Space

Craig Edward Farnham, Kazuo Emura, Takeo Mizuno, Md Ashraful Alam, Jihui Yuan

Paper ID 211116

An Evaluation of Cold Climate Variable Capacity Air Source Heat Pumps in Canadian Residential

Buildings Using an Enhanced Component Model

Stéphanie Breton, Justin Tamasauskas, Martin Kegel

Paper ID 211122

Research on Energy-saving of Adjustable Ventilation Platform Doors System in subway

Yue Zhang, Xiaofeng Li, Bin Wang, Seyedehelham Sadatiseyedmahalleh

Paper ID 211133

An Agent-based Dynamic Occupancy Schedule Model for Prediction of HVAC Energy Demand in an Airport Terminal Building

Kapil Sinha, Nusrat Ali, Rajasekar Elangovan

Paper ID 211147

Heat Pumps In HVAC Systems: Sensitivity Study Of The Simulated Performance Of A Reference

Building At Different Latitudes In Europe

Viola Iaria, Angelo Spena, Carlo Mazzenga

Paper ID 211197

Simulation And Implementation Of A Self-Tuned Hvac Controller

Seungjae Lee, Jaewan Joe, Panagiota Karava, Ilias Bilionis, Thanos Tzempelikos

Paper ID 211423

The Effect Of Room Temperature Control By Air- Or Operative Temperature On Thermal Comfort

And Energy Use.

Bjarne W. Olesen, Haiying Wang, Ongun B. Kazanci

Human behaviour

Paper ID 210136

Do Occupants Change Behaviour When Their Home Is Renovated?

Rune Korsholm Andersen, Jens Kristian Kruse Petersen, Ane Midtstraum

Paper ID 210166

Right on Time - Exploring Suitable Time Discretization for Occupant Behavior Co-Simulation

Romana Markovic, Eva Grintal, Amin Nouri, Jérôme Frisch, Christoph van Treeck

Paper ID 210185

Understanding Occupant Behaviour in Islamic Homes to Close the Gap in Building Performance

Simulation: A Case Study of Houses in Riyadh

Mohammed Aljammaz, Tsung-Hsien Wang, Chengzhi Peng

Paper ID 210195

Simulating the Impact of Occupants on Office Building Design Process: A Case Study

Tareq Abuimara, Burak Gunay, William O'Brien

Paper ID 210196

A Generalized Inhomogeneous Markov Chain Occupancy Model For Open-Plan Offices Using Real

Time Locating System Data

Shide Salimi, Amin Hammad 
Paper ID 210210

Inter-Occupant Diversity in Occupant Behaviour Models: Exploring Potential Benefits for Predicting Light Switch-on Actions

Farhang Tahmasebi, William O’Brien, Yan Wang, Samuel Stamp, Dejan Mumovic, Ardeshir

Mahdavi

Paper ID 210235

Bayesian Inference For Predicting An Inter-Individual Variation Of Thermal Sensation Votes

Jongyeon Lim, Yasunori Akashi, Naoki Yoshimoto

Paper ID 210266

Simulation-based Approach to Assess Occupancy-adaptability of Buildings

William O'Brien, H. Burak Gunay, Mohamed Ouf .

Paper ID 210356

Analysis of Large Scale Air Conditioner User Behaviour in China Based on Data Mining Method

Hua Liu, Mingyang Qian, Da Yan.

Paper ID 210370

Study on Occupancy Prediction for Building Operation using Machine Learning Method

Yuan Jin, Da Yan, Hongsan Sun

Paper ID 210406

Inhabitants' Adaptive Strategies: A Case of Interactive Control in Residential Buildings

Vinu Subashini Rajus, Robert Woodbury

Paper ID 210441

A Bottom-Up Model to Evaluate the Flexibility of French Residential Wet Appliances

Jérôme Le Dréau, Marika Vellei, Yassine Abdelouadoud

Paper ID 210480

Development and Application Implications of Enabling Occupant Behaviour Modelling Within

Building Performance Simulation

Joe Clarke, Andrew Cowie

Paper ID 210486

Profiling Occupant Behaviour in Italian Households for enhanced building simulation input: Insights into a Survey-based Investigation

Verena Marie Barthelmes, Giulia Crespi, Maria Valentina Di Nicoli, Cristina Becchio, Valentina Fabi,

Stefano Paolo Corgnati.

Paper ID 210512

Estimating Thermal Sensation Distribution Using Ordered Probability and Multinomial logit Models

Dayi Lai, Chuanming Chen, Ruoyu You, Chun Chen .

Paper ID 210540

Considering Occupant Behaviour in Building Energy Simulations along the Design Process: From a

Semi-static to a Dynamic Model

Ayu Miyamoto, Karen Allacker, Frank De Troyer.

Paper ID 210628

Simulating The Dynamics Of Occupant Behaviour For Thermal Comfort In Social Housing

Jeetika Malik, Ronita Bardhan, Pradipta Banerji.

Paper ID 210684

Spatial Evaluation of the Effects of Sun Radiation and Clothing Adaptation in Indoor Comfort

Simulations

Jorge Conejo Fernandez, Francesca Cappelletti, Andrea Gasparella.

Paper ID 210685

Comparative Analysis between Typical and Actual Occupancy Profiles on Energy Consumption and

Thermal Comfort Retrofitting Measures: Case Study

Mohamed Amer, Vu Hoang, Christian Frenzel

Paper ID 210749

Simulation Of Photovoltaic Production And Human Activity For Smart Building Energy Management And Sharing

Jérémy ALBOUYS-PERROIS, Nicolas SABOURET, Yvon HARADJI, Mathieu SCHUMANN,

Chrisitian INARD. 
Paper ID 210750

Pattern Recognition And Classification For Electrical Energy Use In Residential Buildings

Martina Ferrando, Alla Marchenko, Silvia Erba, Francesco Causone, Salvatore Carlucci

Paper ID 210786

Occupant Behavior Modelling to Support the Development of Adaptive Facade Control Strategies

Isabella Gaetani, Remco N.P. van Woensel, Pieter-Jan Hoes, Jan L.M. Hensen

Paper ID 210793

Building Performance Implications of Occupant Mobility

Sara Gilani, Rhys Goldstein, Simon Breslav, Alex Tessier, William O'Brien

Paper ID 210794

Influence Of Control And Finishing Of Internal Blinds On The Cooling Energy Consumption Of

Buildings

Mateus Vinícius Bavaresco, Matheus Soares Geraldi, Bruna Faitão Balvedi, Enedir Ghisi

Paper ID 210857

Modeling Decentralized Systems For Energy Savings Based On Detailed Local Thermal Comfort

Calculations

Katharina Boudier, Sabine Hoffmann.

Paper ID 210869

Short-Horizon Probabilistic Models For Whole Home Motion Prediction Using Connected

Thermostat Data

Brent James Huchuk, Scott Sanner, William O'Brien

Paper ID 210897

Planning Building Rehabilitation Projects for Safe Evacuation Provisions - An ABM Approach

Roshanak Eftekharirad, Leila Rafati Sokhangoo, Abdelhadi Hosny, Mazdak Nik-Bakht.

Paper ID 210935

Using a Dynamic Clothing Insulation Model in Building Simulation - Impact on Thermal Comfort and Energy Consumption.

Mohamad Rida, Sabine Hoffmann

Paper ID 210972

Stochastic Occupant Behavior Model Based on Activity And Occupancy Patterns

Silke Verbruggen, Marc Delghust, Jelle Laverge, Arnold Janssens

Paper ID 210995

Numerical Analysis of the Sensitivity to the Occupant Window Opening of the Yearly Energy

Consumptions and of the Indoor Thermal Comfort Conditions in a Series of Reference Cases

Jean Pierre Campana, Gian Luca Morini

Paper ID 211024

Activity Modelling for All National Population based on Population Census and Time Use Data

Yohei Yamaguchi, Hideaki Takenaka, Ken T. Murata, Yuka Kambayashi, Takeshi Okada, Ayako

Taniguchi-Matsuoka, Yuto Shoda, Yoshiyuki Shimoda....

Paper ID 211026

Semi-automated Simulations: Know Your Schedules.

Nilesh Bakshi, Michael Donn, Emily Newmarch

Paper ID 211056

Characterization of Occupant Behaviour Models for Simulation Engineers and Architects

Marcel Schweiker, William O’Brien, Burak Gunay.....

Paper ID 211071

On The Development of an Iot Infrastructure to Perform Behavioural Change Towards Low Energy Habits

Alfonso P. Ramallo-González, Aurora González-Vidal, Pedro J. Fernandez-Ruiz, Antonio F.

Skarmeta-Gómez

Paper ID 211095

Data Preparation to Address Heterogeneity in Time Use Data Based Activity Modelling

Takeshi Okada, Yohei Yamaguchi, Yoshiyuki Shimoda 
Paper ID 211151

An Approach For Obtaining And Extracting Occupancy Patterns In Buildings Based On Mobile

Positioning Data

Xuyuan Kang, Da Yan, Hongsan Sun, Yuan Jin, Peng Xu

Paper ID 211220

'Inside the Box': A Cooperative Game for Co-creating Energy Efficient Retail Spaces

Elli Nikolaidou, Yang Yu, Robert Schmidt-III, Andrew Dainty, Malcolm Cook, Ksenia Chmutina,

Dashamir Marini

Paper ID 211234

Online Building Energy Model to Evaluate Heating and Cooling-related Behavior Changes for Ecofeedback in a Multifamily Residential Building

Sang woo Ham, Panagiota Karava.

Paper ID 211411

Benefits of the Inclusion of Occupant Behaviour Profiles in the Simulation of the Energy Performance of Buildings

Davide Calì, Dirk Müller, Henrik Madsen

Paper ID 211417

Simulation Of Indoor Thermal Environment Control Considering The Probability Of Submitting

Discomfort Sensations From Room Occupants With Different Temperament Types

Fulin Wang, Dianshan Han, Rui Yan

Paper ID 211418

Impact Of Window Opening Behaviors On Cooling Load Of High-Rise Residential Buildings In Hong Kong

Jia Du, Wei Pan

Indoor Environmental Quality (IEQ)

Paper ID 210142

Evaluation of Improved Indoor Environmental Quality during Renovation by the new IV20 Tool

Tine Steen Larsen, Lasse Engelbrecht Rohde, Henrik N. Knudsen, Kim Trangbæk Jønsson, Rasmus

Lund Jensen

Paper ID 210177

Experimental Validation of a CFD-based Air Quality Sensor Placement Strategy for the Localization of Indoor Source Emissions

Julien Waeytens, Sophie Durand, Sara Sadr

Paper ID 210338

Annual Radiation Discomfort: A New Climate-Based Framework For Modeling Short-Wave Solar Radiation In Indoor Spaces

Andrea Zani, Henry David Richardson, Alberto Tono, Stefano Schiavon, Edward Arens

Paper ID 210379

Dynamic Simulation Of A Lighting System Based On The Hue-Heat Hypothesis

Laura Bellia, Francesca Romana D'Ambrosio Alfano, Francesca Fragliasso, Boris Igor Palella,

Giuseppe Riccio..

Paper ID 210420

Smart Passive System for Dehumidification, Cooling, and Heating Utilizing Renewable Energy in Detached House

Haksung Lee, Akihito Ozaki, Wanghee Cho, Myonghyang Lee

Paper ID 210440

Evaluating Dynamic Thermal Comfort under Demand Response Events: a Novel Model Compared against Fanger's PPD Model

Marika Vellei, Jérôme Le Dréau.

Paper ID 210465

Historical Development of IEQ in Danish Dwellings - Has Energy Efficiency Requirements Inhibited Positive IEQ Developments?

Lasse Rohde, Tine Steen Larsen, Rasmus Lund Jensen, Evangelia Loukou, Kim Jønsson. 2458 
Paper ID 210477

Influence of Physiological Variability on Thermal Comfort: A Numerical Evaluation

Edouard Walther, Asit Kumar Mishra, Vincent Forcadell.

Paper ID 210538

Exploring Thermal Comfort Band for Healthcare Workers in Remote Clinics in Hot and Arid

Climates: An Approach for Building Performance Improvement

Samuel Urom Udom

Paper ID 210586

Heat Stress In Residential Buildings As a Result Of Deficient HVAC System

Mayuri Rajput, Godfried Augenbroe

Paper ID 210644

Efficient Indoor Design in Slum Rehabilitation: A Systematic Simulation for Optimized Energy and experiential Indoor Environmental Quality (e-IEQ)

Ahana Sarkar, Ronita Bardhan

Paper ID 210683

Modelling and Mapping Thermal Comfort Conditions with Solar Radiation: Comparison of Steady-

State and Dynamic Indexes

Jorge Conejo Fernandez, Francesca Cappelletti, Andrea Gasparella

Paper ID 210687

Energy And Financial Evaluation Of Thermal Comfort. The Case Study Of The Hotel Residence

L'Orologio

Cristina Becchio, Marta Carla Bottero, Stefano Paolo Corgnati, Federico Dell'Anna, Valentina Fabi,

Carola Lingua

Paper ID 210732

Urban Heat Stress Survivability Simulation under Climate Change Scenarios

Norhan Magdy Bayomi, Tarek Rakha, John E. Fernandez

Paper ID 210826

Implementing Volatile Organic Compounds In CONTAM For Assessment Purposes: A Review

Klaas De Jonge, Jelle Laverge

Paper ID 210907

Impact Of Thermally Activated Furniture System On Thermal Comfort

Rajan Rawal, Vishal Garg, Satish Kumar, Bhargav Adhyaru

Paper ID 210916

Gaussian Process Regression for a PMV Prediction Model using Environmental Monitoring Data

Young Ran Yoon, Sun Ho Kim, Jeong Won Kim, Hyeun Jun Moon.

Paper ID 211070

Metamodeling of Summer Thermal Comfort in a Non-Air-Conditioned Building

Issa Jaffal, Christian Inard, Nesreen Ghaddar, Kamel Ghali

Paper ID 211226

Simulation Assisted Energy Optimization of Abandoned Facilities: An Adaptive Reuse Approach

Rudina Breçani, Rudina Belba, Sokol Dervishi.

Paper ID 211381

Humidifying Without Adding Humidity: Psychrometric Shifts in Humidity from Air Temperature

Setbacks Enabled by Radiant Heating or Cooling

Forrest Meggers, Hongshan Guo, Eric Teitelbaum

Paper ID 211390

Simulation based Indoor Environmental Quality Analysis Of Existing Windows Used In Tropical Office Space

Kwabena Abrokwa Gyimah, Samuel Amos-Abanyie, Christian Koranteng

New software development

Paper ID 210127

A2B: A Toolkit for Computing Circulation Metrics in Buildings

Arash Naderpour, Brian Johnson, Alex Anderson. 
Paper ID 210130

On the Scalability of Equation-Based Building and District Simulation Models

Per Sahlin, Patrik Skogqvist, Alexey Lebedev, Lars Eriksson, Pavel Grozman.

Paper ID 210137

Building Performance Simulation Supporting Typical Design Activities: The Case Of 'Reference

Pictures'

Steffen Petersen, Pil Brix Purup

Paper ID 210273

New Method of Solar Energy Representation for Environmental Analysis Software

Jung Min Han, Ali Malkawi, Krzysztof Gajos

Paper ID 210322

Renewable Energies in Historical Buildings (REHIB project)

Alvaro de Gracia, Joan Tarragona, Anna Laura Pisello, Franco Cotana, Xavier Rodríguez, Josep

Maria Burgués, Luisa F Cabeza, Cèsar Fernández .

Paper ID 210352

Large-Scale Transfer Learning For Data-Driven Modelling Of Hot Water Systems

Hussain Kazmi, Johan Suykens, Johan Driesen.

Paper ID 210353

Energy Transition in Rural Areas - Supporting Local Energy Planning by the Development of an Online-Tool for Identification and Promotion of Energy-Efficiency and the Use of Renewables.

Uwe Caemmerer-Seibel, Andrea Lück, Ammar Osman, Gerd Kiesel, Conrad Völker, Hans Wilhelm

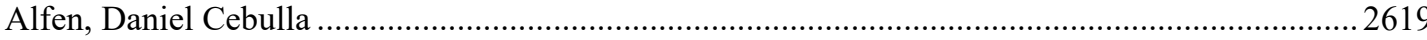

Paper ID 210365

Improving the Collaboration between Architects and Energy Consultants through Design-integrated early BIM-tools

Alexander Hollberg, Matthias Götz, Thomas Lichtenheld, Philipp Hollberg, Galimshina Alina,

Guillaume Habert

Paper ID 210411

A New Tool For The Hygrothermal Simulation Of Building Components: ProCasaClima

Hygrothermal

Marco Larcher, Alexandra Troi, Martina Demattio

Paper ID 210479

FMI-Based Co-Simulation Using Multi-Agent Models Of Occupants Utilizing Modelica Building

And HVAC System Models

Torsten Schwan, René Unger, Tom Eckhardt.

Paper ID 210641

A new MATLAB Simulink Toolbox for Dynamic Building Simulation with B.I.M. and Hardware in the Loop compatibility

Dietmar Siegele, Eleonora Leonardi, Fabian Ochs

Paper ID 210837

A New BIM To BEM Framework: The Development And Verification Of An Open-source gbXML

To EnergyPlus Translator For Supporting Building Life Cycle Performance Analysis

Weili Xu, Adrian Chong, Khee Poh Lam, Haopeng Wang

Paper ID 210839

A Comparison of CSE and EnergyPlus for Residential Energy Calculations

Neal Kruis, Matthew Larson, Bruce Wilcox, Charles S. Barnaby....

Paper ID 210875

Detailed Thermal Comfort Analysis from Preliminary to Final Design

Nathaniel L Jones, Ingrid Chaires, Alexej Goehring

Paper ID 210931

Omegalpes: An Optimization Modeler as an Efficient Tool for Design and Operation for City Energy

Stakeholders and Decision Makers

Camille Pajot, Lou Morriet, Sacha Hodencq, Vincent Reinbold, Benoit Delinchant, Frédéric Wurtz,

Yves Maréchal.

Paper ID 210991

Automatic Simplification Of Complex Building Geometry For Whole-building Energy Simulations.

Luis Santos, Simon Schleicher, Luisa Caldas.. 2691 
Paper ID 211002

Nature 4 Cities: Nature-Based Solutions And Climate Resilient Urban Simulation with Greenpass ${ }^{\circledR}$

Tool And On Site Validation. A Case Study In Segrate/Milano/IT

Mohamed Elagiry, Florian Kraus, Bernhard Scharf, Andrea Costa, Roberto Delotto

Paper ID 211006

An Innovative Energy Representation Tool for Air Conditioning That Enhance Energy Savings and Improve Energy Literacy on Users

Roberto García-Manzano, Alfonso P. Ramallo-González, Ramón Sanchez-Iborra

Paper ID 211189

A Simplified Method For Estimating Cooling Energy Savings Due To Passive Strategies For Indian Cities

Arjun Desai, Prasad Vaidya, Sanchi Pathela, Maaz Barin Dixit

Paper ID 211208

Advances And Challenges For Scalable Cloud-based Infrastructure For Building Data Analysis And Simulation

Thibaud Nesztler, Michael Georgescu

Paper ID 211239

BESP: An Integrated Platform for Building and Environment Simulation

Walter Mazuroski, Ricardo C. L. F. Oliveira, Nathan Mendes.

Paper ID 211276

Prototyping The BOPTEST Framework For Simulation-Based Testing Of Advanced Control

Strategies In Buildings

David Blum, Filip Jorissen, Sen Huang, Yan Chen, Javier Arroyo, Kyle Benne, Yanfei Li, Valentin

Gavan, Lisa Rivalin, Lieve Helsen, Draguna Vrabie, Michael Wetter, Marina Sofos.

Paper ID 211367

Daylight Study from Early to the End of Architectural/Urban Design Process by Developing an Addin for Revit

Majid Miri, Elmira Ashtari

Optimization

Paper ID 210109

From Data Collection To Multi-objective Optimization Of An Existing Solar Thermal Combisystem

Anthony Rey, Radu Zmeureanu

Paper ID 210116

Iterative Building Optimization via Sequential Local Optimization Operations on Distinct Attribute

Clusters of Design Variants

Ardeshir Mahdavi, Shirdel Hamidreza

Paper ID 210143

An Approach of Model-based Predictive Control For Energy Consumption at a Community Level fo

Mathieu Brugeron, Riederer Peter, Frederic Wurtz, Marechal Yves

Paper ID 210156

Multi-Objective Model Predictive Control Framework for Buildings

Krzysztof Arendt, Anders Clausen, Claudio G. Mattera, Muhyiddine Jradi, Aslak Johansen, Christian

T. Veje, Mikkel B. Kjærgaard, Bo N. Jørgensen ..

Paper ID 210157

MShoot: an Open Source Framework for Multiple Shooting MPC in Buildings

Krzysztof Arendt, Christian T. Veje

Paper ID 210173

Optimization of Design and Construction Process of Heat Source System Utilizing BIM

Kazuki Yajima, Yasunori Akashi, Jongyeon Lim, Masahide Fukui

Paper ID 210201

Optimal Heat Pumps Operation For Demand Response of Residential Buildings At District Scale

Camille Pajot, Nils Artiges, Benoit Delinchant, Yves Maréchal....

Paper ID 210255

Design Optimization of Energy Flexibility for Residential Buildings

Alice Mugnini, Fabio Polonara, Alessia Arteconi 
Paper ID 210271

Building Performance Optimization for Operational Rule Extraction

Burak Gunay, Mohamed Ouf, Guy Newsham, William O'Brien....

Paper ID 210304

Electric Energy Consumer Characterization, Classification and Demand Forecasting using

Convolutional Neural Networks

Ignacio Aguirre, Stepan V Ulyanin, Jose R Vazquez-Canteli, Zoltan Nagy .....

Paper ID 210319

Model predictive control applied to a heating system with PV panels and thermal energy storage

Joan Tarragona, Cèsar Fernández, Luisa F. Cabeza, Alvaro de Gracia .....

Paper ID 210336

Existing Energy Performance and The Potential of Role of Simulation in School Building Design - A Review

Ming Hu.

Paper ID 210385

Model Free Optimal Control of Two Whole Buildings using Deep Q-Learning

Ki Uhn Ahn, Jae Min Kim, Youngsub Kim, Cheol Soo Park, Kwang Woo Kim

Paper ID 210423

Optimising Conservation Of Artworks, Energy Performance And Thermal Comfort Combining

Hygrothermal Dynamic Simulation And On-Site Measurements In Historic Buildings

Francesca Frasca, Cristina Cornaro, Elena Verticchio, Anna Maria Siani

Paper ID 210443

Development of a Framework for Model Predictive Control (MPC) in a Large-Sized Office Building

Using Modelica Grey-Box Models

Svenne Freund, Gerhard Schmitz

Paper ID 210472

Multi-Actor Modelling For MILP Energy Systems Optimisation: Application To Collective Self-

Consumption

Lou Morriet, Gilles Debizet, Frédéric Wurtz

Paper ID 210551

Inverse Design of Built Environment by a Fast Fluid Dynamics-based Genetic Algorithm

Yu Xue, Wei Liu.

Paper ID 210555

Energy Efficient Design and Energy Sharing Potential of Urban-Community

Ali Syed, Caroline Hachem

Paper ID 210610

Identification Of Energy, Environmental And Economical Optimal Refurbishment Scenarios For

Hotels In The Alps

Marie-Lise Pannier, Hervé Boileau, Catherine Buhé

Paper ID 210613

Optimization of Cold and Heat Storage Volumes of a Thermal-energetic System with IDA ICE

Marco Borer, Moritz Zwahlen, Manuel Frey

Paper ID 210621

Why we need a Testbed for Black-Box Optimization in Building Simulation

Christoph Waibel, Thomas Wortmann, Georgios Mavromatidis, Ralph Evins, Jan Carmeliet

Paper ID 210625

Embedding Sensitivity Analysis into PSO for Building Energy Optimization

Dan Hou, Wei Yan, Gang Liu, Zhen Han

Paper ID 210631

Energy Saving Potentials of a Centralized Hybrid Heating System via Adaptive Model Predictive

Control in a Northern Italy Residential Building

Ettore Zanetti, Rossano Scoccia, Silvia Garone, Marcello Aprile, Mario Motta, Livio Mazzarella. 2925

Paper ID 210635

Evaluation of Post Processing Analysis to determine Optimal Thermo-Optical Properties for Adaptive

Glazing Systems with Quick Adaptation Speed

Martina Pelle, Francesco Causone, Fabio Favoino, Francesca Contrada, Andrea Kindinis 2933 
Paper ID 210636

A Multi-Stage Framework for Building Energy Optimization: Key Factors and Prototypes

Dan Hou, Wei Yan, Gang Liu, Xiaoqian Li

Paper ID 210664

Model Predictive Control of Building Energy System including Thermal Energy Storage

Doyun Lee, Ryozo Ooka, Shintaro Ikeda, Wonjun Choi, Younghoon Kwak.

Paper ID 210704

Multi-Objective Optimisation of Passivhaus Buildings in a Social Housing Context

Joseph Forde, Christina Hopfe, Rob McLeod, Ralph Evins

Paper ID 210726

Optimizing Energy Conservation Measures in a Grocery Store using Present and Future Weather Files

Arfa N Aijazi, Rob Best, Stefano Schiavon

Paper ID 210734

Metaheuristic Optimization of External Shading Devices and Glazing Properties for Energy Saving and Indoor Environmental Comfort in Office Rooms

Lorenzo De Donatis, Ryozo Ooka, Claudio Del Pero, Wonjun Choi, Fabrizio Leonforte, Shintaro

Ikeda

Paper ID 210808

Simulation of Precooling Strategies in Office Buildings: Deriving Demand Side Management

Potentials

Jonas Müller, Ulrich Reiter, Martin Jakob

Paper ID 210827

Constructing and Exploring School Building Massing Design Spaces Considering Multiple

Performance Objectives

Roya Rezaee, Marionyt Tyrone Marshall, Marcelo Bernal, Nirvik Saha, John Haymaker

Paper ID 210896

Simultaneous Feature Extraction and Non-linear Clustering of Building Energy Profiles Encoded as Images

Stepan Ulyanin, Jose Vazquez-Canteli, Zoltan Nagy

Paper ID 210904

Coupling Parametric Design and Robotic Assembly Simulation to Generate Thermally Responsive Brick Walls

Sherif Morad Abdelmohsen, Khaled Aly Tarabieh, Islam Ibrahim Salem, Yomna Saad El-Ghazi, Rana Bahaa El-Dabaa, Asmaa Gamal Hassan

Paper ID 210929

Reliability-Based Optimization For Energy Refurbishment Of A Social Housing Building

Marco Manzan, Giorgio Lupato, Amedeo Pezzi, Alberto Clarich, Paolo Rosato

Paper ID 210979

Scenario-based HVAC Energy Cost Optimizer for Heterogeneous Heat-source Systems of Real-life Hospital Building

SungHo Park, Ki Uhn Ahn, Seungho Hwang, Sunkyu Choi, Cheol Soo Park

Paper ID 210998

Applying Desirability Functions To Preference Modelling In Low-Energy Building Design

Optimization

Elaine Robinson, Christina J. Hopfe, Michael Emmerich, Iryna Yevseyeva, Jonathan A. Wright ...3030

Paper ID 211127

Hydronic Optimization Of Hybrid Heating Systems: A Methodology Based On Base Circuits

Freek Van Riet, Roel Vandenbulcke, Jonas Cleiren, Ivan Verhaert .

Paper ID 211156

Optimization of Building Form and Fenestration for Current and Future Climate Scenarios Garima Singhal, Devi S, Balaji K, Rajasekar E, Sukumar Natarajan

Paper ID 211157

Two-Step Optimization of Envelope Design for the Reduction of Building Energy Demand

Alberto Barbaresi, Giulia Menichetti, Enrica Santolini, Daniele Torreggiani, Patrizia Tassinari .... 3055 
Paper ID 211178

Influence Of Window To Wall Ratio On Global Energy Consumption Of Nzeb Kindergartens In Italy Cecilia Ciacci, Frida Bazzocchi, Vincenzo Di Naso, Andrea Rocchetti

Paper ID 211201

Data-based Modeling of Building Consumption Profile for Optimal Flexibility: Application to Energy Intensive Industry

Camille Pajot, Quang Hung Nguyen, Benoit Delinchant, Frédéric Wurtz, Yves Maréchal, Stéphane

Robin, Benjamin Vincent, François Debray

Paper ID 211250

Building Energy Use Surrogate Model Feature Selection - A Methodology Using Forward Stepwise

Selection and LASSO Regression Methods

Erica C. Barnes, J.J. McArthur

Paper ID 211278

Simplified Methods For Shading Device Optimization Processes: A Comparison Between Radiance And EnergyPlus For Daylighting Analysis Capabilities

Natália Queiroz, Fernando Simon Westphal, Fernando Oscar Ruttkay Pereira

Paper ID 211291

Optimal Vehicle Selection in the Design of Urban Energy Systems: An Integration of the Private Transport and Building Energy Sectors

Portia Murray, Kristina Orehounig, Jan Carmliet

Paper ID 211294

RNN-based Forecasting of Indoor Temperature in a Naturally Ventilated Residential Building

Kui Weng, Monjur Mourshed

Paper ID 211331

Model Development for Robust Optimal Control of Building HVAC

Saman Mostafavi, Robert Cox, Benjamin Futrell

Paper ID 211372

Early-Design Optimization of Target Ventilation Rates for Hybrid Buildings Using Single-Node

Analytical Model

Alpha Yacob Arsano, Carlos Cerezo Davila, Christoph Reinhart

Paper ID 211373

Adaptive Parametric Algorithm for Optimizing Non-Conventional Solar Screens for South-Oriented

Office Façades in Cairo, Egypt

Asmaa Hassan, Sherif Ezzeldin, Ahmed Abdin

Simulation at urban scale.

Paper ID 210104

Outdoor Thermal Environment of High-rise Residential Area

Meng Zhen, Dian Zhou.

Paper ID 210134

Urban Energy Models Validation in Data Scarcity Context: Case of the Electricity Consumption in the French Residential Sector

Thomas Berthou, Bruno Duplessis, Pascal Stabat, Philippe Rivière, Dominique Marchio

Paper ID 210159

Impact Of Retro-reflective Materials As Urban Coating: A Theoretical And Parametric Study Through Simulations

Mattia Manni, Gabriele Lobaccaro, Francesco Goia, Andrea Nicolini 3148

Paper ID 210180

How To Perform An Efficient Learning Process For A Combined POD And PGD Soil Urban Thermal Model? Application To Canyon Streets.

Marie-Hélène AZAM, Sihem GUERNOUTI, Marjorie MUSY, Philippe POULLAIN 3155

Paper ID 210183

MicroGrid Energy Management Optimization - A Common Platform For Research, Development And Design Tools

Patrick Beguery, Peter Pflaum, Carl Mugnier 
Paper ID 210190

Automatic and Rapid Calibration of Urban Building Energy Models

Yixing Chen, Tianzhen Hong

Paper ID 210232

Application Of Intelligent Algorithms For Residential Building Energy Performance Rating Prediction Usman Ali, Mohammad Haris Shamsi, Cathal Hoare, Fawaz Alshehri, Eleni Mangina, James

O’Donnell

Paper ID 210247

The Effect of Changeable Urban Albedo on Solar Radiation Incident on Vertical Facade

Dominika Knera, Dariusz Heim

Paper ID 210249

Comparing Community Energy Assessment Approaches for UK and India

David Paul Jenkins, Sandhya Patidar, Peter McCallum, Andrew Peacock.

Paper ID 210250

Building Energy Simulations at Urban Scale Based on Standardized Data Models Using a Transparent Enrichment Process

Andreas Geiger, Joachim Benner, Karl-Heinz Häfele, Veit Hagenmeyer

Paper ID 210264

Exploring the Integration of Simulation and Deep Learning Models for Urban Building Energy

Modeling and Retrofit Analysis

Alex Nutkiewicz, Rishee K. Jain

Paper ID 210280

The Effects of Reflective and Permeable Pavements on the Urban Microclimate

Andrea Ferrari, Aytac Kubilay, Dominique Derome, Jan Carmeliet

Paper ID 210290

An Integrated Tool For The Energy And Seismic Diagnosis And Refurbishment Of Buildings At

Urban Scale

Lorenzo Belussi, Ludovico Danza, Matteo Ghellere, Giulia Guazzi, Italo Meroni, Francesco

Salamone, Michele Palermo, Tomaso Trombetti, Sandra Deisvaldi, Paolo Piazza

Paper ID 210301

The Simulation of Mean Radiant Temperature in Outdoor Conditions: A review of Software Tools Capabilities

emanuele naboni, marco meloni, chris makey, jerome kaempf

Paper ID 210320

A Co-simulation Framework for Assessing the Interaction between Heat Pumps and the Low Voltage Grid on a District Scale

Jalomi Maayan Tardif, Jaume Salom, Martin Kegel, Francisco Díaz-González, Alaia Sola

Paper ID 210342

Economic and Ecologic Evaluation of Low Temperature Waste Heat Integration Into Existing District Heating

Dominik Hering, André Xhonneux, Dirk Müller.

Paper ID 210344

Urban-Scale Energy Building Simulation: A Development Of A Novel Method For Parsimonious Modelling - The Example Of Solar Irradiation Calculation

Enora Garreau, Thomas Berthou, Bruno Duplessis, Vincent Partenay, Dominique Marchio

Paper ID 210355

Co-simulation of a Rooftop Greenhouse and a School Building in London, UK

Melanie Kiren Jans-Singh, Rebecca Ward, Ruchi Choudhary

Paper ID 210360

Improving FEM Computations For The Simulation Of Thermograms At The Urban Scale

José Pedro Aguerre, Raphael Nahon, Eduardo Fernández, Benoit Beckers

Paper ID 210383

Nailing the Peak: City-Scale, Building-Specific Load Factor and Contribution to a Utility's Hour of

Critical Generation

Joshua New, Mark Adams, Eric Garrison, Wiliam Copeland, Brian Smith, Andy Campbell 3282 
Paper ID 210402

Modeling Outdoor Thermal Comfort in Urban Canyons: Presentation and Validation of a Novel Comprehensive Workflow

Gianpiero Evola, Emanuele Naboni, Giuseppe Margani, Cristina Magri'

Paper ID 210418

Buildings' Performance Simulations For Urban Scale Energy Demand Modelling In The Interreg

Projects Idee And Ueb

Massimiliano Condotta, Tiziano Dalla Mora, Giovanni Borga, Fabio Peron

Paper ID 210424

A Comparison of Bottom-up and Top-down Modelling Approaches in Urban Energy Simulation for the Assessment of City District Data Models

Anja Willmann, Lara Katscher, Thomas Leiser, Conrad Voelker

Paper ID 210425

The Impact of Using Typical Weather with Spatial Variations on Thermal Mass Design for Reducing the Mortality Risk and Building Peak Load in India

Woong June Chung, Francesca Cecinati, Chunde Liu, Elangovan Rajasekar, David Coley, Sukumar

Natarajan

Paper ID 210434

Modelling And Developing A Neighbourhood Low Carbon System For Five Dwellings In The U.K.

Xiaojun Li, Shan Shan Hou, Joanne Patterson, Emmanouil Perisoglou, Miltiadis Ionas, Huw Jenkins,

Phil Jones, Simon Lannon, Ester Coma Bassas

Paper ID 210448

Evaluating Energy and Flexibility Performance of Building Clusters

Ilaria Vigna, Ina De Jaeger, Dirk Saelens, Marco Lovati, Roberto Lollini, Roberta Pernetti

Paper ID 210457

Simplified Mathematical Model for Analyzing the Effects of Urban Heat Island by using WRF and

Building Thermal Simulations

Ivan Oropeza-Perez.

Paper ID 210467

Individual Domestic Hot Water Profiles for Building Simulation at Urban Scale

Verena Weiler, Ursula Eicker

Paper ID 210470

Impact of Residential Energy Consumption on Urban Heat Island Effect in Tainan

Feng-Yi Lin, Ruey-Lung Hwang, Tzu-Ping Lin.

Paper ID 210478

A Review of the Status of Uncertainty and Sensitivity Analysis in Urban Building Energy Models

Pamela Jane Fennell, Paul A Ruyssevelt, Érika Mata, Martin Jakob

Paper ID 210544

Microclimate Data For Building Energy Modelling: Study On ENVI-Met Forcing Data

Agnese Salvati, Maria Kolokotroni

Paper ID 210545

Information Mining for Urban Building Energy Models (UBEMs) from Two Data Sources:

OpenStreetMap and Baidu Map

Chao Wang, Yanxia Li, Xing Shi.

Paper ID 210553

Development Of A Modeling Framework For Refined Residential Occupancy Schedules In An Urban

Energy Model

Diba Malekpour Koupaei, Farzad Hashemi, Vinciane Tabard-Fortecoëf, Ulrike Passe

Paper ID 210563

Handeling 3D Model Of A Street For An Urban Thermal Study With The Finite Element Method

Nicolas Duport, Jairo Acuña Paz y Miño, Benoit Beckers

Paper ID 210568

Linear Discriminant Analysis for Classification of a Large Virtual Smart Meter Data Set With Known Building Parameters

Adam Neale, Michaël Kummert, Michel Bernier 3393 
Paper ID 210574

Proper Choice Of Urban Canopy Model For Climate Simulations

Zahra Jandaghian, Umberto Berardi

Paper ID 210595

Classifying Urban Geometry Impact on Solar Radiation

anas m.hosney lila, simon lannon.....

Paper ID 210597

Modelling Of Non-Residential Building Stocks Based On End-Use Energy Consumptions And

Bayesian Calibration

Deuk Woo Kim, Dong Hyuk Yi, Cheol Soo Park, Yu Min Kim, Seoung-Eon Lee

Paper ID 210603

A Simulation Approach For The Optimization Of Distributed Energy Supply Systems Based On

Energy Demands In Business Area.

Takahiro Ueno, Kentaro Takahashi, Daisuke Sumiyoshi

Paper ID 210607

Parametric Study of the Different Level of Detail of CityGML and Energy-ADE Information for Energy Performance Simulations

Avichal Malhotra, Maksim Shamovich, Jérôme Frisch, Christoph van Treeck

Paper ID 210624

Development of Energy Demand Estimation Model of Japanese Commercial Building Considering

Diversity of Energy Conservation Measurement

Takuya Kitamura, Yohei Yamaguchi, Bumjoon Kim, Kotone Akizawa, Yoshiyuki Shimoda

Paper ID 210630

Restorative Design of Urban Brownfields, an Interdisciplinary Approach Interconnecting Nature-

Based Solutions, Heritage Requalification and Human Wellbeing. A Case Study in Rome

Maria-Beatrice Andreucci, Luciano Cupelloni, Marco Delli Paoli, Silvia Coccolo

Paper ID 210632

An Overview Of Urban Building Energy Modelling (UBEM) Tools

Martina Ferrando, Francesco Causone..

Paper ID 210650

A Multi-Scale Consideration of Daylight in a Real Urban Context

Antoine Bugeat, Eduardo Fernández, Benoit Beckers, José Aguerre

Paper ID 210655

Sustainable Urban Community Eco-Feedback through Simulation-enabled Performance Dashboards

Tarek Rakha, Elena Echarri, Elizabeth Krietemeyer, Jason Dedrick.

Paper ID 210663

Determining The Most Appropriate Form Of Urban Building Energy Model For The City Of

Ahmedabad

Pamela Jane Fennell, Paul A Ruyssevelt, Rajan Rawal, Veeren Poola

Paper ID 210669

Simulation of Hourly Energy Needs at Urban Scale: A Methodology of Adapted Modeling

Eui-Jong Kim, Martin Garcia Perez, Frédéric Kuznik, Jean-Jacques Roux

Paper ID 210670

Dynamic Simulation Of Bidirectional Low-Temperature Networks - A Case Study To Facilitate The Integration Of Renewable Energies

Tobias Blacha, Michael Mans, Peter Remmen, Dirk Müller

Paper ID 210676

Urban Green and Blue Infrastructure Simulation in a Changing Climate from Microclimate to Energy

Consumption: A Case Study in Alexandria, Egypt

Ahmed Ayad, Mohammad Fahmy, Wael Kamel.....

Paper ID 210686

On The Design Of An Urban Modeling Platform And Its Application For A New York District

Analysis

Ursula Eicker, Juergen Schumacher, Verena Weiler, Reiner Braun. 
Paper ID 210694

A CBA-based Model To Evaluate The Retrofit Of A Reference District

Cristina Becchio, Marta Carla Bottero, Stefano Paolo Corgnati, Federico Dell'Anna, Chiara

Delmastro, Elisa Pesce, Giulia Vergerio.

Paper ID 210698

Evaluating The Potential Energy Savings Of An Urban Green Infrastructure Through Environmental

Simulation

Massimo Palme, Daniele La Rosa, Riccardo Privitera, Giacomo Chiesa

Paper ID 210707

Using Model Calibration To Improve Urban Modeling

Louis Leroy, Samuel Letellier-Duchesne, Michaël Kummert

Paper ID 210716

High Resolution Bottom-up Residential Electrical Model For Distribution Networks Planning

Simon Sansregret, Karine Lavigne, Brice Le Lostec, Laurencelle Francois, Frederic Guay.....

Paper ID 210719

Simplified Heat Load Profile Generation

Clemens Felsmann, Peter Stange

Paper ID 210737

Evaluation of Energy Performance of Smart Community Considering Occupant's Behavior

Yuki Kitagawa, Monica I. C. Gondokusuma, Yoshiyuki Shimoda

Paper ID 210771

Assessing The Impact Of The Climate Change In German Building Stocks

Yuchen Yang, Vahid Nik.

Paper ID 210806

Towards a DESTEST: a District Energy Simulation Test Developed in IBPSA Project 1

Dirk Saelens, Ina De Jaeger, Felix Bünning, Michael Mans, Alessandro Maccarini, Enora Garreau,

Øystein Rønneseth, Igor Sartori, Annelies Vandermeulen, Bram van der Heijde, Lieve Helsen ..... 3569

Paper ID 210811

Hybrid Model for Energy Consumption Forecasting in Buildings Stocks at Tropical Regions

José Antonio Bello Acosta, Hugo Franco, Jimeno Fonseca

Paper ID 210846

A Novel Approach to Evaluate the Impacts of Urban Form on the Micro-climate in the Dense Areas

Kavan Javanroodi, Vahid M. Nik .....

Paper ID 210874

Campus Energy Use Prediction (CEUP) Using Artificial Intelligence (AI) to Study Climate Change Impacts

Soheil Fathi, Ravi Srinivasan, Robert Ries

Paper ID 210878

Energy Performance Comparison Of A High Density Mixed Use Building To Traditional Building Types

Wesley Bowley, Ralph Evins

Paper ID 210902

Evaluating Buildings' Solar Energy Potential Concerning Urban Context Based On UAV

Photogrammetry

Yunsong Han, Yongjie Pan, Tianyu Zhao, Cheng Sun.

Paper ID 210917

Clustering As A Simplification Tool For The Decision-Making Process On Building Stock

Renovation

Mathieu Rivallain, Sergei Agapoff, Pierre Boisson, Aurélie Foucquier, Yunseok Lee

Paper ID 210919

Primary-energy Based Optimization of a New Building District through Simulations on Flat,

Building, Block and District Level

Georgios Dermentzis, Fabian Ochs, Alexander Thuer 
Paper ID 210923

Quantifying Uncertainty Propagation For The District Energy Demand Using Realistic Variations On Input Data

Ina De Jaeger, Glenn Reynders, Dirk Saelens

Paper ID 210934

Optimal Design Strategies to Improve Evacuation Safety of Community with Large-Scale Blocks

Yanyu Wang, Cheng Sun, Le Fan

Paper ID 210982

Complete Numerical Evaluation of the BIPV's Production and Envelope Temperatures in Urban

Areas.

Blaise Raybaud, Philippe Thony, Jean-Jacques Roux, Vergnault Etienne, Merlier Lucie

Paper ID 210984

Delivery of Contracted Energy Flexibility from Communities

Rami El Geneidy, Bianca Howard.

Paper ID 210997

Speed Optimization of Simulation Models for Rapid Performance Evaluation of Heating and Energy

Management Systems

James Allan, Max Boegli, Andrew Bollinger, Pierre-Jean Alet, Matthias Wiget

Paper ID 211008

Building Energy Modeling at District Scale Through BIM Based Automatic Model Generation -

Towards Building Envelope Optimization

Mathias Bouquerel, Sébastien Bermes, Adrien Brun, Hassan Bouia, Régis Lecussan, Benoît Charrier3676

Paper ID 211020

District-level Energy Matching Tool For Carbon-free District Concepts

Ari Laitinen, Francesco Reda, Ala Hasan

Paper ID 211022

Local Energy Mapping for Enabling Area-Based Energy Reductions

Rajat Gupta, Matt Gregg.

Paper ID 211048

Co-simulation Workflow for the Dynamic Modelling and Simulation of Large-scale District Energy Systems

Peter Nageler, Gerald Schweiger, Thomas Mach, Richard Heimrath, Hermann Schranzhofer, Lisa

Marie Fochler, Christoph Hochenauer, Ingo Leusbrock, Jürgen Fluch, Christian Fink

Paper ID 211100

Required Specification of Residential End-use Energy Demand Model for Application to National

GHG Mitigation Policy Making - Case Study for the Japanese Plan for Global Warming

Countermeasures

Minami Sugiyama, Ayako Taniguchi-Matsuoka, Yohei Yamaguchi, Yoshiyuki Shimoda

Paper ID 211137

Quantifying the Impact of Urban Microclimate in Detailed Urban Building Energy Simulations

Georgios - Evrystheas Kyriakodis, Emmanuel Bozonnet, Peter Riederer.

Paper ID 211169

A Novel Hybrid Technique For Building Demand Forecasting Based On Data-driven And Urban

Scale Simulation Approaches

Giovanni Tardioli, Ruth Kerrigan, Michael Oates, James O'Donnell, Donal P. Finn.

Paper ID 211210

From Urban Climate to Building and Material Scale: a Multiscale Modelling Approach

Dominique Derome, Aytaç Kubilay, Jonas Allegrini, Andrea Ferrari, Jan Carmeliet.

Paper ID 211211

Intelligent Cosimulation To Consider Urban Climate In Building Energy Simulation

Adrien Gros, Nathan Mendes, walter mazuroski, Ricardo C. L. F. Oliveira ...

Paper ID 211233

Optimal Retrofitting Measures For Residential Buildings At Large Scale: A Multi-Objective

Approach

Portia Murray, Mathias Niffeler, Georgios Mavromatidis, Kristina Orehounig. 
Paper ID 211253

Standardized Representation Of Typological Data As Common Input For Urban Performance

Simulation

Sebastian Ebertshäuser, Petra von Both

Paper ID 211270

Water Cycle Impacts of Residential Water Demand in an Aquifer-based Municipal Water Supply and

Treatment System: Model Development, Implementation, and Case Studies

Shirley Morque, Mansour Sodaghari, Robert John Ries

Paper ID 211271

Energy Consumption of Institutional Buildings Considering the Urban Climate in Rome

Massimo Palme, Carola Clemente, Serena Baiani, Claudia Calice, Agnese Salvati

Paper ID 211272

Impact Of Urban Microclimate On The Energy Performance Of Riad-type Buildings

Adnane M'Saouri El Bat, Zaid Romani, Emmanuel Bozonnet, Abdeslam Draoui

Paper ID 211330

Urban-scale Building Energy Consumption Platform: A Case Study and An Interface for Wuhan

Chao Ding, Wei Feng, Qin Tian

Paper ID 211334

Analysis of Urban Heat Island Phenomenon and Mitigation Strategies for Tirana, Albania

Vilma Picari, Sokol Dervishi

Paper ID 211421

CFD Simulations Of Cross Natural Ventilation Through An Apartment With Modified Inflow Boundary Conditions

Sumei Liu, Wuxuan Pan, Xiaorui Lin, Ke Qing, Weizhen Zhang, Zhengwei Long, Qingyan Chen 3794

Simulation to support regulations

Paper ID 210153

Improving the Energy Performance of Existing Buildings: Search for Opportunities for Social

Housing Companies

Els Van de moortel, Karen Allacker, Frank De Troyer, Luc Stijnen, Erik Schoofs

Paper ID 210261

Dynamic Simulations for Inhomogenous Components

Giorgio Baldinelli, Francesco Bianchi, Agnieszka Lechowska, Jacek Schnotale

Paper ID 210312

Forming a Unitary Envelope Thermal Performance Index for Office Buildings in Taiwan

Ruey-Lung Hwang, Ming-Chin Ho, I-Ting Lai, Kuo-Tsang Huang

Paper ID 210313

An Atlas for Residential Earth Building Thermal Performance in Australia Climates

Dong Chen, Zhengen Ren

Paper ID 210346

A Density-Based Spatial Cluster Analysis Supporting The Building Stock Analysis In Historical

Towns

Elena Lucchi, Valentina D'Alonzo, Dagmar Exner, Pietro Zambelli, Giulia Garegnani

Paper ID 210380

Simulation of the Annual Energy Demand of Buildings through Averaged Monthly and Hourly

Calculation Methods: a Comparative Analysis

Fabio Fantozzi, Carlo Romeo, Giacomo Salvadori, Francesco Leccese, Federico Gazzarri

Paper ID 210431

The Dynamic Model of EN ISO 52016-1 for the Energy Assessment of Buildings Compared to

Simplified and Detailed Simulation Methods

Ilaria Ballarini, Andrea Costantino, Enrico Fabrizio, Vincenzo Corrado

Paper ID 210535

Effect Of Grid Tariffs On Demand-side Management In All-electric Buildings In Norway

Sophie Schönfeldt Karlsen, Stian Backe, Mohamed Hamdy 
Paper ID 210575

Benchmarking Building Energy Consumption Using Efficiency Factors

Mahnameh Taheri, Parag Rastogi, Colin Parry, Alan Wegienka.

Paper ID 210602

A Comparative Analysis Among Standard Load Profiles for Natural Gas Consumption Simulation at Urban Scale

Laura Canale, Gino Cortellessa, Marco Dell'Isola, Giorgio Ficco, Andrea Frattolillo, Fabrizio Zuena3871

Paper ID 210627

CFD Analysis Of Airflow In Voids For Better Cross Ventilation In Midrise Buildings In Hot And

Humid Climates

Nikhil Kumar, Tetsu Kubota, Ronita Bardhan, Yoshihide Tominaga

Paper ID 210651

Evaluating Building Energy Code Compliance and Savings Potential through Large Scale Simulation with Models Inferred by Field Data

Yulong Xie, Mark Halverson, Rosemarie Bartlett, Yan Chen, Michael Rosenberg, Todd Taylor, Jeremiah Williams

Paper ID 210692

A Methodology to Quantify the Impact of Building Energy Code Upgrades on Building Energy

Savings: A Case Study on Small Offices

Yunyang Ye, Kathryn Hinkelman, Jian Zhang, Yulong Xie, Wangda Zuo

Paper ID 210709

DC Power Distribution in Buildings - Reliability and Flexibility Simulation

YI BAO, Wei Feng, Huijie Xue, Rich Brown, Bruce Nordman, Daniel Gerber, Jie Wang, Fulin Wang,

Bin Hao, Yutong Li

Paper ID 210720

Test Of ISO 52016-1 Energy Performance Of Buildings Calculation Procedure

Clemens Felsmann, Alf Perschk, Richard Franke

Paper ID 210741

Impact of Building Energy Code at City Level Energy Consumption - A Study in the Context of

Ahmedabad, India

Rajan Rawal, Kartikay Sharma, Himani Pandya

Paper ID 210769

Reference Model for the Analysis of Energy Consumption Characteristics in Accommodation and Cultural Facilities

Suhyun Lee, Hyejin Son, Doun Kim, Jeong-A Kang, Young-Sun Jeong, Sun-Hye Mun, Jung-Ho Huh, Younghoon Kwak.

Paper ID 210775

Weather Data for Building Simulation: Grid Resolution for Climate Zone Delineation

Renjith Jayapalan Nair, Eleonora Brembilla, Christina Hopfe, John Mardaljevic

Paper ID 210805

Application of A Housing Technology Assessment Simulation Platform in Regulation R\&D

Rasoul Asaee, Alex Ferguson, Adam Wills.

Paper ID 210809

Dynamic Simulation to identify Cost-Optimal Energy Requirements for the Italian Building Stock

Vincenzo Corrado, Ilaria Ballarini, Giovanna De Luca, Elisa Primo

Paper ID 210884

Climatic Zoning Methodology Based On Data-Driven Approach

Leonardo Mazzaferro, Rayner Maurício E Silva Machado, Ana Paula Melo, Roberto Lamberts .... 3955

Paper ID 210905

Energy Performance of Desiccant and Evaporative Cooling-assisted 100\% Outdoor Air System

Combined with a Thermoelectric Module and Organic Rankine Cycle

Soo-Yeol Yoon, Joon-Young Park, Seongyong Cheon, Su Liu, Jae-Weon Jeong

Paper ID 210915

Evaluating Daylight Factor Standard through Climate Based Daylight Simulations and Overheating

Regulations in Estonia

Francesco De Luca, Martin Kiil, Raimo Simson, Jarek Kurnitski, Rein Murula 
Paper ID 211019

Development of RETV (Residential Envelope Transmittance Value) Formula for Cooling Dominated Climates of India for the Proposed Energy Conservation Building Code for Residential Building (ECBC-R)

Prashant Kumar Bhanware, Pierre Jaboyedoff, Sameer Maithel, Ashok Lall, Saswati Chetia, Vernica Prakash Kapoor, Satyendra Rana, Salil Mohan, Saurabh Diddi, Abdullah Nisar Siddiqui, Anju Singh, Anand Shukla

Paper ID 211025

Comparative Analysis of Fenestration Systems: A Life Cycle Energy Based Approach

Akriti Singh, Avlokita Agrawal, Aman Batish

Paper ID 211088

Heatwave Vulnerability Assessment of Nursing Homes Based on Dynamic Simulations

Dóra Szagri, Balázs Nagy, Zsuzsa Szalay

Paper ID 211098

The Effect of Using Locally Defined Thermal Conditions on Energy Demand in Hot-Arid Regions

Saif Rashid, Oliver Kornadt, Conrad Voelker

Paper ID 211102

Energy And Fire Safety Performance Of Atrium Ventilation In High-rise Buildings

Haohan Sha, Dahai Qi

Paper ID 211143

Building Performance Simulation in Brazil: A systematic review

Adriano Felipe Oliveira Lopes, Caio Frederico e Silva

Paper ID 211166

Developing Envelope Trade-off Coefficients Using Annual Energy Simulations and Multiple Linear Regressions

Mayank Bhatnagar, Hisham Ahmad, Tanmay Tathagat, Sourabh Diddi, Piyush Varma

Paper ID 211305

Cold Climate Air Source Heat Pumps with Energy Storage: Evaluating the Impacts of a Carbon

Reduction Strategy for New England

Bryan Urban

Paper ID 211314

The Effect of Dynamic Primary Energy Factors On Building Energy Performance

Kjartan Van den Brande, Sam Hamels, Jelle Laverge, Michel De Paepe, Arnold Janssens, Marc

Delghust

Paper ID 211342

A Thermal Performance Labelling System For Windows In Brazilian Residential Buildings

Fernando Simon Westphal, Fabiola Deckert Arndt, Martin Ordenes

Paper ID 211345

Automating Baseline Models for Code Compliance with Energy Conservation Building Code of India

Nikunj Shukla, Mayank Bhatnagar, Piyush Varma, Hisham Ahmad, Gurneet Singh, Tanmay Tathagat, Anurag Biswas, Robin Jain

Paper ID 211370

Designing to TEDI, TEUI, and GHGI Performance Metrics

Jeanie Chan, Andrea Frisque, Anika Jang .....

Paper ID 211405

EN ISO 52016-1: The New International Standard To Calculate Building Energy Needs for Heating

And Cooling, Internal Temperatures And Heating And Cooling Load

Dick van Dijk

Simulation vs reality

Paper ID 210128

Modeling and Performance Simulation of a Retail Store as a Smart Grid Ready Building

Muhyiddine Jradi, Henrik Engelbrecht Foldager, Rasmus Camillus Jeppesen, Jakob Hviid, Mikkel

Ask Rasmussen, Mikkel Kjærgaard. 
Paper ID 210141

Pre Design Renovation Measurements And Efficient Decision-Making. Danish Case Study

Hagar Elarga, Christina Thomsen, Rune Korsholm Andersen, Carsten Rode

Paper ID 210181

Building Simulation to Measure Indoor Microclimate in Heritage Buildings

Kristian Fabbri, Marco Pretelli, Anna Bonora

Paper ID 210186

Remote Sensing For Building Energy Simulation Input - A Field Trial

Philip Gorzalka, Jacob Estevam Schmiedt, Joachim Göttsche, Bernhard Hoffschmidt, Magdalena

Linkiewicz, Dhruvkumar Patel, Stefan Plattner, Christian Schorn, Dirk Frommholz

Paper ID 210216

Study on Management and Control of a District Heating and Cooling Plant

Toshiki Doyama, Michihiro Kondo, Hiroshi Imaoka, Daisuke Sumiyoshi, Hiroki Kitayama, Jongyeon

Lim, Yasunori Akashi

Paper ID 210237

Comparison of Energyplus Simulation Results of Double Skin Facade System with CFD and

Experiment Data

Junghyon Mun, Jongik Lee, Brian Baewon Koh

Paper ID 210296

A Comparison Study Of Simulation-Based Prediction Tools For Air Temperature And Outdoor

Thermal Comfort In A Tropical Climate

Elif Esra Aydin, J. Alstan Jakubiec, Steve Kardinal Jusuf

Paper ID 210327

Data-driven Approach for Modeling the Thermal Dynamics of Residential Buildings Using a

PieceWise ARX Model

Mohammed Hichem Benzaama, Lala Rajaoarisoa, Stéphane Lecoeuche, Balsam Ajib

Paper ID 210351

Exploring The Sky Longwave Radiance Distribution In The French Basque Country

Raphaël Nahon, Jairo Acuña Paz Y Miño, Benoit Beckers .....

Paper ID 210389

The Digital Twin As A Base For The Design Of Building Control Strategies

Christoph Nytsch-Geusen, Werner Kaul, Jörg Rädler, Visvesh Shenoy, Pruthviraj Balekai

Paper ID 210422

Towards Assessing Houses Robustness Against Thermal Stresses Using Temporal Sensitivity Analysis

Léa Gondian, Jeanne Goffart, Monika Woloszyn, Etienne Wurtz, Catherine Buhé, Philippe

Maréchal

Paper ID 210436

The Construction of Minimum Variables Set for Energy Prediction Models of Office Buildings

Mingya Zhu, Yiqun Pan, Zhizhong Huang....

Paper ID 210439

Dynamic Simulation of existing buildings: considerations on the Model Calibration.

Adriana Angelotti, Micol Ballabio, Livio Mazzarella, Cristina Cornaro, Gianmarco Parente, Francesca Frasca, Alessandro Prada, Paolo Baggio, Ilaria Ballarini, Giovanna De Luca, Vincenzo Corrado .. 4165

Paper ID 210468

Validated Simulation of Low Cost Thermal Envelope Upgrades for Slum Housing

Nadir Bonaccorso, Nuno R. Martins, Guilherme Carrilho da Graça

Paper ID 210482

Development Of A Reduced Order Model For Standard-Based Measurement And Verification To

Support ECM

Alessandro Piccinini, Letizia D'Angelo, Federico Seri, Conor Deane, Raymond Sterling, Andrea

Costa, Alberto Giretti, Marcus M. Keane

Paper ID 210484

Bayesian Network for Predicting Energy Consumption in Schools in Florianópolis - Brazil

Matheus Soares Geraldi, Mateus Vinicius Bavaresco, Enedir Ghisi 
Paper ID 210511

PV Optimized Control of Modulating Heat Pumps regarding PV Self-Consumption

Christina Betzold, Arno Dentel

Paper ID 210525

Explicit Representations of Common Artefacts in Simulation

Jon William Hand .

Paper ID 210572

Overview Of A Large Scale Monitoring Project Of Energy Efficient Houses: Complementarity

Between Simulations And Measurements.

Jeanne Goffart, Monika Woloszyn, Xavier Faure, Frederic Wurtz, Léa Gondian, Catherine Buhé,

Thomas Recht, Laurent Mora, Bruno Peuportier, Patrick Schalbart, Manar Aymari, Stéphane Ploix,

Patrice Schneuwly, Etienne Wurtz

Paper ID 210620

Identification of Dwelling-specific Energy Saving Benchmarks from Building Stock Models

John Allison, Joe Clarke

Paper ID 210730

Improvement in Accuracy of Heat Load Calculation for Irregularly used Rooms

Yuki Ebihara, Tatsuo Nagai

Paper ID 210763

Model and Validation of a Multi-family Building 'Haus M' Using Modelica

Josué Borrajo Bastero, Eline Himpe, Martin Ménard, Anne Caminade, Jelle Laverge

Paper ID 210804

Forecasting Indoor Temperatures During Heatwaves: Do More Complex Models Provide Better

Predictions?

Matej Gustin, Rob S. McLeod, Kevin J. Lomas

Paper ID 210859

Energy Modelling of Livestock Houses: the Results from the EPAnHaus Project

Andrea Costantino, Enrico Fabrizio

Paper ID 210977

Comparison Between Two Energy Dynamic Tools : the Impact of Two Different Calculation

Procedures on the Achievement of nZEBs Requirements

Laura Pompei, Fabio Nardecchia, Benedetta Mattoni, Fabio Bisegna, Alessandro Mangione..

Paper ID 210983

Revisiting the Comfort Parameters of ISO 7730: Measurement and Simulation

Mark B Luther, Tarek MF Ahmed.

Paper ID 210994

A Robust Unsupervised Framework for High-resolution Building Energy Consumption Profiling

Sicheng Zhan, Adrian Chong

Paper ID 211074

A Data-Driven Load Shape Profile Based Building Benchmarking: Comparing Doe Reference

Buildings With A Large Metering Dataset

June Young Park, Clayton Miller, Zoltan Nagy

Paper ID 211101

CFS Model Improvement based on Measured Data of a 1:1 Scale Test Mock-up

Marion Hiller, Martin Gut, Holst Stefan.

Paper ID 211113

Predicted And Measured Performances Of Near Zero-Energy Houses: A Comparison Methodology

Thomas Recht, Jeanne Goffart, Laurent Mora, Monika Woloszyn, Catherine Buhe

Paper ID 211161

Predicting Speech Intelligibility In University Classrooms Using Geometrical Acoustic Simulations

Giulia Fratoni, Dario D'Orazio, Domenico De Salvio, Massimo Garai.

Paper ID 211228

Resilient Design and Adaptive Thermal Comfort in the Tropics

Daniel Zepeda-Rivas, Jorge Rodríguez-Álvarez. 
Paper ID 211237

Comparison of Predicted Energy Performance Using Three Software Packages and Measured

Building Performance Evaluation Results

Filbert Musau, Andrew Evans

Paper ID 211268

Accuracy Of HVAC Load Predictions: Validation Of EnergyPlus And DOE-2 Using An Instrumented Test Facility

Philip Haves, Baptiste Ravache, Andres Fergadiotti, J. Christian Kohler

Paper ID 211274

The Use Of Infrared Thermography And Thermoaeraulic Simulation To Approach The Real

Performance Of Existing Buildings

Hajar Ben Hmidou, Zaid Romani, Mohamed El Mankibi, Abdeslam Draoui

Paper ID 211292

Create and Validate Hybrid Ventilation Components in Simulation Using Grasshopper and Python in Rhinoceros

Hoda Barzegar Ganji, Dennis Michael Utzinger, David E Bradley

Paper ID 211343

Evaluation and simulation of neighborhood energy consumption: Case study in Guayaquil, Ecuador Luis Godoy, Catalina Vallejo, Francis Vásquez, Geovanna Villacreses, Andrea Lobato, Karl Heinz Gaudry

Paper ID 211353

Daylighting Performance In Schools Between Simulation Predictions And Field Verifications - A

Factor of Reality Analysis

Ihab Elzeyadi, Belal Abboushi

Paper ID 211413

Annual Energy Consumption Evaluation Of Naturally Ventilated Double Skin Façade In Hot Summer And Cold Winter Zone

Cong Li, Youming Chen, Yanjin Wang

Solar systems

Paper ID 210154

Simulation Examination about Heat Balance of Detached House with the Air-based Solar Heating System

Youngjin Choi

Paper ID 210262

Energy Performance And Occupancy-Based Analysis Of Visual And Thermal Comfort For

Transmittance Level And Layout Variations Of Semi-Transparent Photovoltaics

Giorgia Chinazzo, Adrien Legrain, Giuseppe Peronato, Jan Wienold, Marilyne Andersen

Paper ID 210278

The Influence of Convection on the Behaviour of a Ventilated BIPV Module: A Sensitivity Analysis

Juliana E. Gonçalves, Twan A. J. van Hooff, Dirk Saelens

Paper ID 210282

Simulation of Unglazed Solar Thermal Systems Integrated into Façade \& Combined with Ultra-Low

Temperature District Heating

Mikel Lumbreras, Roberto Garay ......

Paper ID 210548

PVT Systems: Effect of Both Storage Features and Load Configuration

Laura Cirrincione, Cristina Malara, Concettina Marino, Antonino Nucara, Giorgia Peri, Matilde

Pietrafesa

Paper ID 210666

Applied Strategy Using Reflectors to Improve Electricity Generation of Photovoltaic Panels on Buildings

Khalid Osman Abdulkadir, Moon Keun Kim. 
Paper ID 210725

Using Clustering Techniques to Optimize Panel Grouping for Large PV Arrays with Non-uniform Orientation and Shading Obstructions.

Andy McNeil

Paper ID 210760

Early Design Tool For PV+Battery Sizing: An Approach To Maximize The Economic Outlook Of BIPV By Increasing Self-Consumption

Mattia Dallapiccola, Marco Lovati, Jennifer Adami, David Moser

Paper ID 210802

Modeling and Performance Optimization of the Glass Evacuated U-tube Solar Collector

Xiaomeng Chen, Fang Guo, Xudong Yang

Paper ID 210812

Dynamic Performance of a Solar Hybrid Heating Network Integrated with a Micro-Cogeneration Unit Serving a Small-Scale Residential District including Electric Vehicles

Antonio Rosato, Antonio Ciervo, Giovanni Ciampi, Michelangelo Scorpio, Francesco Guarino, Sergio Sibilio

Paper ID 210959

Modeling of Partially Shaded BIPV Systems With BPS Tools - Towards Model Complexity Selection for Early Stage Design Support

Ádám Bognár, Roel Loonen, Jan Hensen

Paper ID 211062

Thermal and Electric Storage Optimization for Solar-Assisted Heat Pump Systems in Residential Buildings

Maria Pinamonti, Paolo Baggio

Paper ID 211121

Using Rhinoceros Plugins Grasshopper And Ladybug To Assess BiPV Façades In Brasília.

Jader de Sousa Freitas, Joára Cronemberger, Raí Mariano Soares

Paper ID 211168

A New Method to Evaluate Environmental Conditions for Appropriate Sizing of PV-Battery Systems

Alfonso P. Ramallo-González, Roel Loonen, Jan Hensen.

Paper ID 211416

Investigation Of The Flow Between A PV Panel And Building's Outer Skin Comprising A Naturally Ventilated BIPV System

Soteris Kalogirou

Validation, calibration and uncertainty

Paper ID 210176

Reliability And Sensitivity Of Building Performance Simulation Tools In Simulating Mechanically Ventilated Double Skin Facades

Adrienn Gelesz, Elena Catto Lucchino, Francesco Goia, András Reith, Valentina Serra

Paper ID 210209

A Comparative Study of Various Sensitivity Analysis Methods in Building Application

Zhihong Pang, Zheng O'Neill

Paper ID 210246

Uncertainty Quantification In Predictive Modelling Of Heat Demand Using Reduced-order Grey Box Models

Mohammad Haris Shamsi, Usman Ali, Fawaz Alshehri, James O'Donnell

Paper ID 210263

Empirical Validation of Building Energy Modeling using Flexible Research Platform

Piljae Im, Joshua R. New, Jaewan Joe

Paper ID 210350

Calibration of a Hybrid Heat Pump System and Application of an Energy Manager in Building

Performance Simulations

Philipp Mehrfeld, Martin Steinbach, Markus Nürenberg, Moritz Lauster, Dirk Müller 
Paper ID 210381

Accuracy Of The Most Popular Building Performance Simulation Tools: Experimental Comparison For A Conventional And A PCM-Based Test Box

Domenico Mazzeo, Piercarlo Romagnoni, Nicoletta Matera, Giuseppe Oliveti, Cristina Cornaro, Livio

De Santoli

Paper ID 210460

Deploying Building Simulation To Enhance The Experimental Design Of A Full-Scale Empirical

Validation Project

Eirini Mantesi, Konstantinos Mourkos, Christina Hopfe, Rob McLeod, Paraskevi Vatougiou, Matthias

Kersken, Paul Strachan.

Paper ID 210562

Municipal Heating Grid Load Predictions for Improved Control of Heating and Cogeneration Plants

Aneta Strzalka, Jacek Kalina, Rafal Strzalka, Ursula Eicker.

Paper ID 210570

A Robust Approach For The Calibration of the Material Properties in an Existing Wall

Alessandro Prada, Andrea Gasparella, Paolo Baggio

Paper ID 210577

A Framework For The Continuous Calibration Of Building Energy Models With Uncertainty

Adrian Chong, Song Chao

Paper ID 210588

Developing Equivalent Surface Heat Transfer Input Parameters for Updated Standard 140/BESTEST

Thermal Fabric Test Cases

Joel Neymark, Michaël Kummert, Ron Judkoff

Paper ID 210592

Development of Test Procedure for the Evaluation of Building Energy Simulation Tools - Phase II

Expansion of Evaluation Targets and Results of Simulation Trials -

Eikichi Ono, Sei Ito, Harunori Yoshida.

Paper ID 210649

A Framework for Understanding the Uncertainty Across Energy Model Stages and Methodologies

Patrick Alan Pease, Nada Tarkhan, Chan Mi Hwang

Paper ID 210718

Calibrated simulation of a NZEB: The Solar Decathlon China 2018 SCUTxPoliTo Prototype

Ciro Lisciandrello, Maria Ferrara, Alessio Messina, Enrico Fabrizio

Paper ID 210768

Method For Building Model Calibration Based Upon On-Site Temperature Data To Simulate

Overheating Risk In A Passive House In Summer

Pauline Abrahams, Philippe André, Marie Lang, Claudia Falzone

Paper ID 210803

Now It Looks More Real - A Study of Metrics and Resolution for the Calibration of Building and HVAC Simulation

Aurelien Bres, Frédéric Amblard, Jessen Page, Stefan Hauer, Anna Shadrina

Paper ID 210840

Validation and Application of a Numerical Code for Estimate Energy Performance of Complex

Glazing Systems Based on Semi-transparent Organic Photovoltaics Elements

Santiago Riquelme, Nathan Mendes, Luís Mauro Moura.

Paper ID 210852

Calibrating Energy Performance Model of a Hospital Building: Dealing with Practical Issues of Data

Availability and Granularity in a Case Study Building in the UK.

Nishesh Jain, Esfand Burman, Dejan Mumovic, Michael Davies

Paper ID 210879

Verification of Probabilistic Building Energy Models

Qinpeng Wang, Godfried Augenbroe

Paper ID 210882

Uncertainty Analysis of the Representation of Air-Handling Unit with Terminal VAV Boxes in

EnergyPlus

Qinpeng Wang, Godfried Augenbroe 
Paper ID 210891

Modelling the Influence of Layout On Overheating Risk of London Flats

Andrea Lorena Vallejo Espinosa, Phil Symonds, Giorgos Petrou

Paper ID 210925

Characterization Of Building Foundation In Building Energy Models

Germán Ramos Ruiz, Vicente Gutierrez González, Eva Lucas Segarra, Germán Campos Gordillo,

Carlos Fernandez Bandera

Paper ID 210975

Identifiability Of The Heat Transfer Coefficient In Buildings With Unheated Spaces

Sarah Juricic, Peder Bacher, Jeanne Goffart, Simon Rouchier, Aurélie Foucquier, Gilles Fraisse .. 4666

Paper ID 211033

Hygrothermal Simulations Comparative Study: Assessment of Different Materials Using WUFI and

DELPHIN Software

Bina Hejazi, Nayara Rodrigues Marques Sakiyama, Jürgen Frick, Harald Garrecht

Paper ID 211109

Refinement of Dynamic Non-Residential Building Archetypes Using Measurement Data and Bayesian Calibration

Peter Remmen, Julian Schäfer, Dirk Müller

Paper ID 211110

A Framework to Quantify Data Informativeness in Risk-Conscious Building Performance Simulation Applications

Qi Li, Godfried Augenbroe, Jason Brown .....

Paper ID 211148

Development and Validation of PCM Models Integrated Into the High Order Building Model of

Modelica Library - Aixlib

Akbar Halimov, Moritz Lauster, Dirk Müller

Paper ID 211173

Uncertainty Propagation of Internal Heat Gains for Building Thermal Behavior Assessment: Influence of Spatial Distribution

Jordan Gauvrit, Antoine Caucheteux, Stéphane Lecoeuche

Paper ID 211182

Calibration for Stochastic Existing Building Stock Model for Energy Simulation

Hye-Gi Kim, Sun-Sook Kim.

Paper ID 211302

Empirical Validation of Single-Room Heat Transfer Models under Uncertainty

Qi Li, Ralph Muehleisen, Baptiste Ravache, Philip Haves

Paper ID 211325

Characterization Of HVAC Operation Uncertainty In EnergyPlus AHU Modules

Di Sui, Yuna Zhang, Godfried Augenbroe

Paper ID 211410

Evaluating Input Influence in Grey-box models for Demand Response in Buildings

Harald Taxt Walnum, Karen Byskov Lindberg, Igor Sartori.

Weather

Paper ID 210122

Urban climate - Impact on energy consumption and thermal comfort of buildings

Urs Grossenbacher, Jan Remund

Paper ID 210126

Utilization of Satellite-based Remote-sensing for the Representation of External Boundary Conditions in Building Energy Modelling

Pelin Firat Ors, Milena Vuckovic, Ardeshir Mahdavi

Paper ID 210189

On the Prediction of Ground-Reflected Solar Radiation and its Relevance in the Context of Building Performance Simulation (BPS)

Luminita Dumitrascu, Ian Beausoleil-Morrison 
Paper ID 210243

A New Approach to Model the Effect of Climate Change on the Building Sector: a Climate Models

Data Fusion

Giovanni Tumminia, Francesco Guarino, Daniele Croce, Sonia Longo, Ilenia Tinnirello, Marco

Ferraro, Marina Mistretta, Maurizio Cellura

Paper ID 210328

Testing Typical Indian Buildings Under Different Extreme Temperature Conditions

Francesca Cecinati, Woong J. Chung, Sukumar Natarajan, David A. Coley

Paper ID 210515

A Projection And Clipping Method To Calculate Direct, Diffuse, And Reflected Irradiation

Jacob Estevam Schmiedt, Björn Schiricke

Paper ID 210521

Architect-friendly Analysis Tool For Bioclimatic Design In Hot Humid Climates

Shady Attia, Theo Lacombe

Paper ID 210527

Creation Of Future Probabilistic Hot Event Years For Assessing Building Resilience To Heatwaves

Chunde Liu, Woong June Chung, Coley David.

Paper ID 210594

Should We Be Using Just ‘Typical' Weather Data in Building Performance Simulation?

Drury Crawley, Linda Lawrie

Paper ID 210746

Integration Of Convection Permitting Climate Models By Means Of Typical and Extreme Years in Building Energy Simulations In A Context Of Climate Change

Delphine Ramon, Karen Allacker, Nicole P.M. van Lipzig

Paper ID 210777

Nowcasting Methods For Optimising Building Performance

$\mathrm{Hu} \mathrm{Du}$, Carlos Fernández Bandera, Lei Chen

Paper ID 210877

Assessing Building Energy Performance via Selection of Representative Simulation Days

Yan Chen, Saptarshi Bhattacharya, Zhihong Pang, Deepak Sivaraman, Sen Huang, Draguna Vrabie4825

Paper ID 210938

Clustering of European Climates and Representative Climate Identification for Building Energy

Simulation Analyses

Giovanni Pernigotto, Angélica Walsh, Andrea Gasparella, Jan LM Hensen

Paper ID 211159

Climate Zone Classification of India Using New Base Temperature

Mayank Bhatnagar, Jyotirmay Mathur, Vishal Garg

Paper ID 211389

Using Satellite-Derived Solar Radiation to Create Weather Files of Unprecedented Accuracy and Reliability

Yu Joe Huang

Windows

Paper ID 210228

Sensor Selection and Control Strategy Development Support for Automated Solar Shading Systems

Using Building Performance Simulation

Samuel De Vries, Roel Loonen, Jan Hensen

Paper ID 210272

A Comparative Study on the Energy Performance of Movable Insulation and Triple-Glazed Windows

Zhaoyun Zeng, Jason Brown, Godfried Augenbroe

4863

Paper ID 210559

Actuation Of Changeable Optical Properties By A Construction Node Temperature - An Example Of

PCM-Window

Anna Wieprzkowicz, Dariusz Heim 
Paper ID 210564

Modelling The Performances Of An Innovative Shading Device Integrating PV

Emanuele Piccoli, Alessandro Dama...

Paper ID 210642

Seasonal Optimization of Dynamic Thermo-Optical ETFE Façade System

Jung Min Han, Daekwon Park

Paper ID 210675

Modeling a Ventilator with Multiple Modes of Ventilation and Air Filtration

Facheng Li, Tengfei Zhang, Shugang Wang

Paper ID 210908

A Comparison Of The Latest Window Modeling Methods In EnergyPlus

J. Christian Kohler, Peter Lyons, Robert G. Hart, D. Charlie Curcija

Paper ID 211013

Occupant-Centred Control Strategies For Adaptive Facades: Preliminary Study Of The Impact Of

Shortwave Solar Radiation On Thermal Comfort

Alessandra Luna Navarro, Juan Diego Blanco Cadena, Fabio Favoino, Mattia Donato, Tiziana Poli,

Marco Perino, Mauro Overend

Paper ID 211065

Artificial Neural Network Based Model Predictive Control Vis-à-Vis Simple On-Off Control Of

Windows Opening Position For Mixed-Mode-Operated Building

Brijesh Pandey, Rajat Pungaliya, Rangan Banerjee.

Paper ID 211107

Modelling Of Complex Fenestration Systems - Application Of Different Toolchain Approaches On

Real Case Scenarios

Martin Hauer, Giuseppe De Michele, Francesco Babich, Daniel Plörer, Stefano Stefano

Paper ID 211287

A Fast GPU Algorithm for Complex Fenestration Systems Optimization

Ignacio Decia, Eduardo Fernández, Pablo Ezzatti

Paper ID 211312

Energy Performance of Offices Buildings in Brazil using Insulated Glass Units

Mônica Martins Pinto, Fernando Simon Westphal.

Paper ID 211414

Comparative Analysis of Three Calculation Models to Simulate Energy Performance of Aerogel

Glazing System

Dongmei Zheng, Youming Chen, Yaling Xiao, Yang Liu, Yupeng Li, Siqian Zheng, Bin Lu

Zero Energy Buildings (ZEB)

Paper ID 210199

Simulation-assisted Optimization of NZE Multi-family Buildings

Fabian Ochs, Georgios Dermentzis, Monteleone William

Paper ID 210291

The Contribution Of Geothermal Heat Pumps In Net Zero Energy Buildings (NZEBs)

Diana D'Agostino, Luigi Mele, Francesco Minichiello

Paper ID 210363

Robustness of Building Design Integrating Phase Change Materials in Nordic and Mediterranean Climates

Juan Manuel Cruz, Francesco Goia, Albert Castell

Paper ID 210399

Design of a Low Energy Consumption Office Building using Dynamic Simulations

Tiberiu Catalina, Guillaume Menegaldo, Catalin Lungu, Valentin Gavan, Gheorghe Ilisei

Paper ID 210428

Social Housing In Italy: Energy Audit And Dynamic Simulation Towards A nZEB Policy

Alice Lorenzati, Ilaria Ballarini, Giovanna De Luca, Vincenzo Corrado..... 
Paper ID 210450

Energy Efficiency and Grid Flexibility through Building To Vehicle To Buildings Approach:

Modelling and Simulation

Giovanni Barone, Annamaria Buonomano, Cesare Forzano, Gaetano Galano, Adolfo Palombo .... 4998

Paper ID 210469

A Simulation Study of Typical Green Houses in Beijing: PAR (Photosynthetically Active Radiation)

Performances and Energy Consumption

Yang Wang, Jiangtao Du, Daoliang Li

Paper ID 210546

Green vs Traditional Roofs: Assessing their Actual Benefits through an Integrated Indicator

Developed for Cool Roofs

Maria La Gennusa, Concettina Marino, Antonino Nucara, Giorgia Peri, Gianfranco Rizzo, Gianluca

Scaccianoce.

Paper ID 210672

Sensitivity Analysis of Glazing Parameters and Operational Schedules on Energy Consumption and Life Cycle Cost

Mohamed Amer, Waqas Ahmed Mahar, Guirec Ruellan, Shady Attia

Paper ID 210679

Retrofit Scenarios for Emissions Reduction in Italian Hotels Towards a Post-Carbon City

Giulia Crespi, Cristina Becchio, Stefano Paolo Corgnati

Paper ID 210747

Optimized Solutions For Thermal And Visual Comfort In The Design Of A Nearly Zero-Energy Building

Giovanna De Luca, Ilaria Ballarini, Argun Paragamyan, Anna Pellegrino, Vincenzo Corrado

Paper ID 210772

Combining design and operational optimization of a NZEB: The Solar Decathlon China 2018

SCUTxPoliTo Prototype

Alessio Messina, Maria Ferrara, Ciro Lisciandrello, Enrico Fabrizio

Paper ID 210822

Investigating the Energy and Thermal Implications of Installation of an Air Curtain and an Automatic Door in Convenience Stores in Wales

Shan Shan Hou, Joanne Patterson, Xiaojun Li, Emmanouil Perisoglou, Phil Jones

Paper ID 210996

Simulation-based Methodology For Comparison Of nZEB Requirements In Different Countries Including Results Of Model Calibration Tests

Carsten Wemhoener, Lukas Rominger, Simon Buesser, Mara Magni, Fabian Ochs, Christina Betzold, Thomas Dippel.

Paper ID 211155

Evaluating the Potential of High Performance Concrete 3D-Printed Affordable Zero Energy Homes

Paola Sanguinetti, Khaled Ali Almazam, Omar Abdulmughni Humaidan, Joe James Colistra ..... 5068

Paper ID 211209

Investigation of the Model Structure for Low-Order Grey-Box Modeling of Residential Buildings

Xingji Yu, Laurent Georges, Michael Dahl Knudsen, Igor Sartori, Lars Imsland.....

Paper ID 211213

Moving Towards Net Zero - Improving Thermal Comfort and Energy Performance of Prototype

Supermarket Stores in India

Vaibhav Rai Khare, Maaz Akbar Khan, Hisham Ahmad, Tanmay Tathagat, Rohan Parikh

Paper ID 211257

Potential of Mid-Rise Social Residential Buildings to Reach Net Zero Energy Building Standard in Two Different Climates of Chile

Felipe Tori, Sergio Vera, Waldo Bustamante, Pablo Sills

Paper ID 211264

Rooftop Greenhouses: Energy And Environmental Synergies Of Bidirectional Integration With The Building.

Joan Muñoz-Liesa, Mohammad Royapoor, Elisa López-Capel, Eva Cuerva, Santiago Gassó-Domingo, Alejandro Josa 5097 
Paper ID 211339

Ultra-Low Carbon Technologies for Building Retrofits

Samantha Alyce Lane, Randy Irwin, Andrea Frisque, Jeanie Chan

Addendum

Paper ID 210306

Energy Management System (EMS): The Impact of Natural Ventilation and Shading Control on Thermal Performance of University Building in Winnipeg, Canada

Ali Mohammadzadeh, Miroslava Kavgic, Ali Al-janabi

Paper ID 210309

Impact of Building Form on Energy Performance in New School Models

Meriem Rahmani, Khaled Al-Sallal 